\title{
Comparative Transcriptome Analyses in Zymoseptoria tritici Reveal Significant Differences in Gene Expression Among Strains During Plant Infection
}

\author{
Javier Palma-Guerrero, ${ }^{1}$ Xin Ma, ${ }^{1}$ Stefano F. F. Torriani, ${ }^{1,2}$ Marcello Zala, ${ }^{1}$ Carolina S. Francisco, ${ }^{1}$ \\ Fanny E. Hartmann, ${ }^{1}$ Daniel Croll, ${ }^{1}$ and Bruce A. McDonald ${ }^{1}$ \\ ${ }^{1}$ Plant Pathology, Institute of Integrative Biology, ETH Zurich, 8092 Zurich, Switzerland; and ${ }^{2}$ Syngenta Crop Protection AG, \\ Schaffhauserstrasse, 4332 Stein, Switzerland
}

Accepted 23 January 2017.

\begin{abstract}
Zymoseptoria tritici is an ascomycete fungus that causes Septoria tritici blotch, a globally distributed foliar disease on wheat. $Z$. tritici populations are highly polymorphic and exhibit significant quantitative variation for virulence. Despite its importance, the genes responsible for quantitative virulence in this pathogen remain largely unknown. We investigated the expression profiles of four $Z$. tritici strains differing in virulence in an experiment conducted under uniform environmental conditions. Transcriptomes were compared at four different infection stages to characterize the regulation of gene families thought to be involved in virulence and to identify new virulence factors. The major components of the fungal infection transcriptome showed consistent expression profiles across strains. However, strain-specific regulation was observed for many genes, including some encoding putative virulence factors. We postulate that strain-specific regulation of virulence factors can determine the outcome of $Z$. tritici infections. We show that differences in gene expression may be major determinants of virulence variation among $Z$. tritici strains, adding to the already known contributions to virulence variation based on differences in gene sequence and gene presence/absence polymorphisms.
\end{abstract}

Variation in transcription among individuals can explain a significant fraction of the phenotypic diversity within a species (Oleksiak et al. 2002). This variation is expected to increase with genetic distance among related individuals (Whitehead and Crawford 2006). Transcriptomics generally aims to characterize the landscape of mRNA levels within an individual under a variety of physiological and developmental conditions, but it can also be used to identify transcriptional differences between species or among individuals of the same species. Many interspecific comparative transcriptome studies have been performed in filamentous fungi. For example, by comparing the

Nucleotide sequence data were deposited into the National Center for Biotechnology Information Short Read Archive under the accession number SRP077418.

Corresponding author: J. Palma-Guerrero; E-mail: javier.palma@usys.ethz.ch

*The $e$-Xtra logo stands for "electronic extra" and indicates that 13 supplementary figures and 12 supplementary tables, and four other supplementary files are published online.

(C) 2017 The American Phytopathological Society expression patterns of different Neurospora species during sexual development, Lehr et al. (2014) identified and validated novel genes involved in sexual reproduction. Other transcriptome comparisons considered the interaction of different Trichoderma mycoparasites with Rhizoctonia solani (Atanasova et al. 2013), differences between Metarhizium anisopliae and M. acridum during early insect infection (Gao et al. 2011), and responses to hypoxia in different Aspergillus species (Terabayashi et al. 2012). Until now, intraspecific transcriptome comparisons were limited to model organisms (Whitehead and Crawford 2006) and no studies considered plant-pathogenic fungi.

The filamentous ascomycete fungus Zymoseptoria tritici (syn. Mycosphaerella graminicola) causes Septoria tritici blotch on wheat (Triticum aestivum L.) and is considered the most damaging wheat pathogen in Europe (Jorgensen et al. 2014; O'Driscoll et al. 2014). Z. tritici provides an excellent model for intraspecific comparative transcriptomic studies. Natural field populations are large and undergo frequent recombination, leading to very high levels of genetic diversity and rapid evolution (McDonald and Linde 2002; Wittenberg et al. 2009; Zhan and McDonald 2004; Zhan et al. 2003). Most measured traits, including virulence, are quantitative, consistent with additive actions of many genes (Stewart and McDonald 2014; Stewart et al. 2017; Zhan et al. 2007) and indicating that a fine-tuned regulation of different virulence components may be needed for successful colonization of the host. A finished reference genome is available (Goodwin et al. 2011), and many Z. tritici genomes have already been resequenced (Croll et al. 2013; Torriani et al. 2011).

The Z. tritici disease cycle begins with spore germination on wheat leaves, followed by penetration through stomata and a period of asymptomatic extracellular growth in the apoplast that lasts nine to 14 days, depending on the strain. This latent phase has been called 'biotrophic,' but no specialized feeding structures associated with biotrophic pathogens, such as haustoria, have been observed in Z. tritici (Kema et al. 1996). It is thought that secreted effectors, including LysM, prevent recognition by the plant and actively suppress host defenses during this extended asymptomatic phase (Kellner et al. 2014; Lee et al. 2014; Marshall et al. 2011; Palma-Guerrero et al. 2016; Rudd et al. 2015). After the latent phase, large numbers of plant cells are killed during a period of approximately 48 to $72 \mathrm{~h}$, making nutrients available for fungal metabolism. This necrotrophic stage is accompanied by a rapid increase in fungal biomass inside the plant (Rudd et al. 2015). Subsequently, the pathogen forms heavily melanized asexual fruiting structures called pycnidia in the substomatal cavities of the dead plant 
tissue. At this point, the pathogen enters into the saprotrophic stage of its life cycle, continuing to grow and form fruiting structures in the already dead plant tissue, eventually producing the sexual fruiting bodies (pseudothecia) approximately six to eight weeks following the initial infection. Z. tritici can continue to survive as a saprophyte on the colonized straw for at least nine months (Scott et al. 1988).

Despite the agricultural importance of this pathogen, the mechanisms and genetics underlying its pathogenicity remain poorly understood. Some genes involved in $Z$. tritici virulence have been described and functionally characterized, but most of them have regulatory functions rather than a specific role in virulence. Compared with other important fungal pathogens, the number of characterized virulence factors in $Z$. tritici is relatively low (Rudd 2015).

Transcriptomic studies of $Z$. tritici during wheat infection improved our understanding of the interaction between wheat and Z. tritici during the infection process (Kellner et al. 2014; Palma-Guerrero et al. 2016; Rudd et al. 2015). These studies showed that the transition to necrotrophy coincides with an increase in expression of pathogen genes encoding small secreted proteins (SSPs) that may act as effectors (PalmaGuerrero et al. 2016; Rudd et al. 2015). These SSPs were shown to play important roles in the suppression of plant defenses in other pathogen-plant interactions but, in Z. tritici, deletion of SSP-encoding genes that are up-regulated at the onset of necrotrophy did not affect disease progression (Gohari et al. 2015; Poppe et al. 2015; Rudd et al. 2015). We recently reported concerted transcriptional regulation of families of genes involved in pathogen attack, including proteases, lipases, and plant cell wall-degrading enzymes (PCWDEs) during the transition to necrotrophy (Palma-Guerrero et al. 2016). In addition, we compared the transcriptomes of the Dutch reference strain (IPO323) and a Swiss strain (ST99CH_3D7) during different phases of the infection cycle and identified conserved major virulence components between the strains but also found that expression of SSPs, proteases, and PCWDEs was highly strainspecific. However, a major weakness of this comparison is that the data were obtained from independent experiments conducted in different labs that used different experimental conditions, including different host cultivars ('Riband' and 'Drifter'), so it was not possible to determine whether differences in hosts, pathogen strains, or environments were responsible for the observed differences in gene expression.

To better understand the contribution of differential gene expression to virulence, we performed a comparative transcriptomic study under common garden conditions (de Villemereuil et al. 2016), i.e., in a uniform biotic and abiotic environment shared by all strains. Transcriptomic profiles of four Z. tritici strains with previously characterized virulence phenotypes (Stewart et al. 2017; Zhan et al. 2002, 2005) on a single host were performed. To our knowledge, this is the first study to compare transcriptomes of different strains of a fungal plant pathogen under common garden conditions across an infection cycle. This approach allowed us to identify core elements of the $Z$. tritici infection transcriptome that play an important role in virulence. In addition, we found differential expression and presence/ absence polymorphisms of candidate virulence factors. Overall, this comparative transcriptomic analysis identified several factors that may explain quantitative differences in virulence among strains.

\section{RESULTS AND DISCUSSION}

Fungal transcriptome analyses of wheat leaf infection.

Four previously characterized Z. tritici strains (ST99CH_1A5, ST99CH_1E4, ST99CH_3D1, and ST99CH_3D7, abbreviated as
1A5, 1E4, 3D1, and 3D7), collected in 1999 from two Swiss wheat fields and differing for many quantitative traits, including virulence (Lendenmann et al. 2014; Zhan et al. 2002, 2005), were used to inoculate the susceptible wheat cultivar Drifter (Triticum aestivum L. cv. Drifter). These strains were previously used as parents for quantitative trait loci mapping studies (Lendenmann et al. 2014; Stewart et al. 2017). The genomes of all four strains have been resequenced (National Center for Biotechnology Information [NCBI] BioSample accession numbers SRS383146 [3D1], SRS383147 [3D7], SRS383142 [1A5], and SRS383143 [1E4]) and have been analyzed for gene and chromosomal polymorphisms (Croll et al. 2013; Torriani et al. 2011). The four strains are genetically equally distant from each other with approximately 310,000 single-nucleotide polymorphisms distinguishing each pair of isolates. The 3D7 strain was used in earlier transcriptomic studies (Brunner et al. 2013; Palma-Guerrero et al. 2016). Clear differences in disease progression were observed for the four strains, including different durations for the latent period (Fig. 1A). The earliest symptoms of infection were observed at 12 days postinfection (dpi) for the most virulent strain 3D7, consistent with earlier findings (Palma-Guerrero et al. 2016). First symptoms for 3D7, 1A5, and 1E4 were visible at 14 dpi but were less severe for 3D1. At $28 \mathrm{dpi}$, pycnidia were most abundant for 3D7 and 1E4, moderately abundant for 3D1, and almost absent on leaves infected by 1A5 (Fig. 1A). This pattern was consistent with previous results obtained using these strains (Stewart et al. 2017).

Over one billion reads were collected for each strain (Table 1). The percentage of reads mapped to the fungal genome increased slowly during the asymptomatic phase and more quickly following symptom development (Fig. 1B; Table 1). This increase in fungal reads is consistent with a rapid increase in fungal biomass following the transition to necrotrophy (Rudd et al. 2015). Consistent with the macroscopic virulence phenotype, strain 3D7 showed the fastest increase in mapped reads while strain 3D1 had the slowest. 1E4 and 1A5 showed similar mapping values at all time points, lying between 3D1 and 3D7 at day 14. No differences in mapped reads were observed among strains at 28 dpi (Fig. 1B; Table 1). We found the greatest variation among biological replicates at 12 and $14 \mathrm{dpi}$. This most likely reflects variation in rates of disease progression, as a result of either small differences in applied inoculum, small differences in microenvironments, or both coupled with small differences in growth and development of the inoculated plants, which had larger effects during the transition from the asymptomatic to the necrotrophic phase. Nevertheless, most biological replicates clustered according to time points (Supplementary Fig. S1).

The genome of the reference strain IPO323 comprises 10,933 annotated gene models (Goodwin et al. 2011). The reannotation of IPO323 based on RNA-seq data generated 11,839 gene models, of which 10,048 have RNA-seq support (Grandaubert et al. 2015). After combining the transcriptomes across all four time points for each strain, we obtained evidence for 10,072 expressed genes in 3D1, 10,013 in 3D7, 10,045 in 1A5. and 10,103 in 1E4. Genes located on accessory chromosomes were expressed at much lower levels than genes found on the core chromosomes for all four strains (Supplementary Fig. S2), as has been previously reported for IPO323 (Kellner et al. 2014; Rudd et al. 2015).

\section{Analysis of different gene categories relevant for virulence.}

We conducted a detailed analysis of different gene categories associated with fungal virulence, including SSPs, secreted proteases, secreted PCWDEs, secreted lipases, secreted peroxidases, and genes encoding polyketide synthases (PKSs). 
SSPs are putative effector proteins produced by a pathogen to modulate physiological and morphological processes in its host (Rep 2005). In this study, we considered SSPs to be proteins of less than 300 amino acids containing more than $5 \%$ cysteine residues and predicted to be secreted, according to Grandaubert et al. (2015). A total of 121 genes encoding proteins with these properties were identified (Supplementary Table S1) and their transcription profiles were compared across the four $Z$. tritici strains. The overall SSP expression patterns were similar among the four tested strains (Fig. 2). The global peak of SSP expression preceded the first visual symptoms on the leaves, i.e., 12 dpi for 3D7 and 1A5, which are the strains showing the faster necrotic symptoms on the leaves, and to $14 \mathrm{dpi}$ for 3D1 and 1E4, which showed longer latent periods (Fig. 2B). All four strains shared five genes encoding SSPs that were not transcribed at any time point (2_00651,9_00125, 7_00156, 7_00750, and 1_00178) (Figs. 2A and 3). These could be pseudogenes or may not play a role during infection on 'Drifter'. Three additional nontranscribed genes encoding SSPs (11_00002, 8_00609, and 12_00155) were absent in the genomes of the four Swiss strains compared with IPO323. Other genes encoding SSPs showed strain-specific expression or a presence/absence polymorphism. For example, 11_00006 was not expressed in 3D7 or 1A5 at any time point but was missing only in 3D7; 13_00329 was absent in both 1A5 and 1E4, while 1_01094 was present and expressed in $1 \mathrm{E} 4$ but missing in the genomes of the other three strains; 7_00832 was only expressed in 1E4, but it is missing only in the genomes of 3D7 and 1A5. The remaining genes encoding SSPs were present in all four genomes, but some of them were not expressed at one or more time points in one or more strains. However, these four strains may contain other SSPs that are absent from the IPO323 genome that our analysis may have missed by using the IPO323 annotation. Based on analyses of SSPs in other plant-pathogenic fungi (de Jonge et al. 2011; Rep 2005), we postulate that all of the SSP-encoding genes that exhibit presence/absence polymorphisms or strain-specific differences in expression could be involved in coevolutionary processes that led to the loss or silencing of those genes to avoid recognition by the plant and activation of plant defense mechanisms.

A
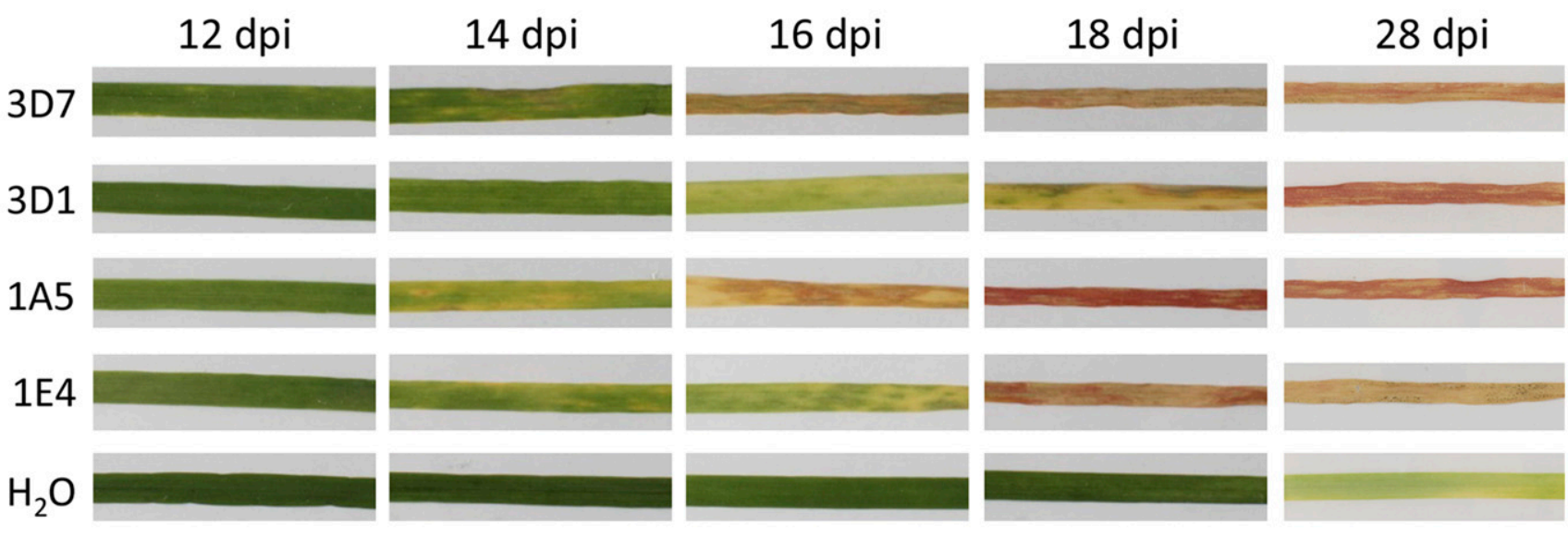

B

\% Fungal Reads

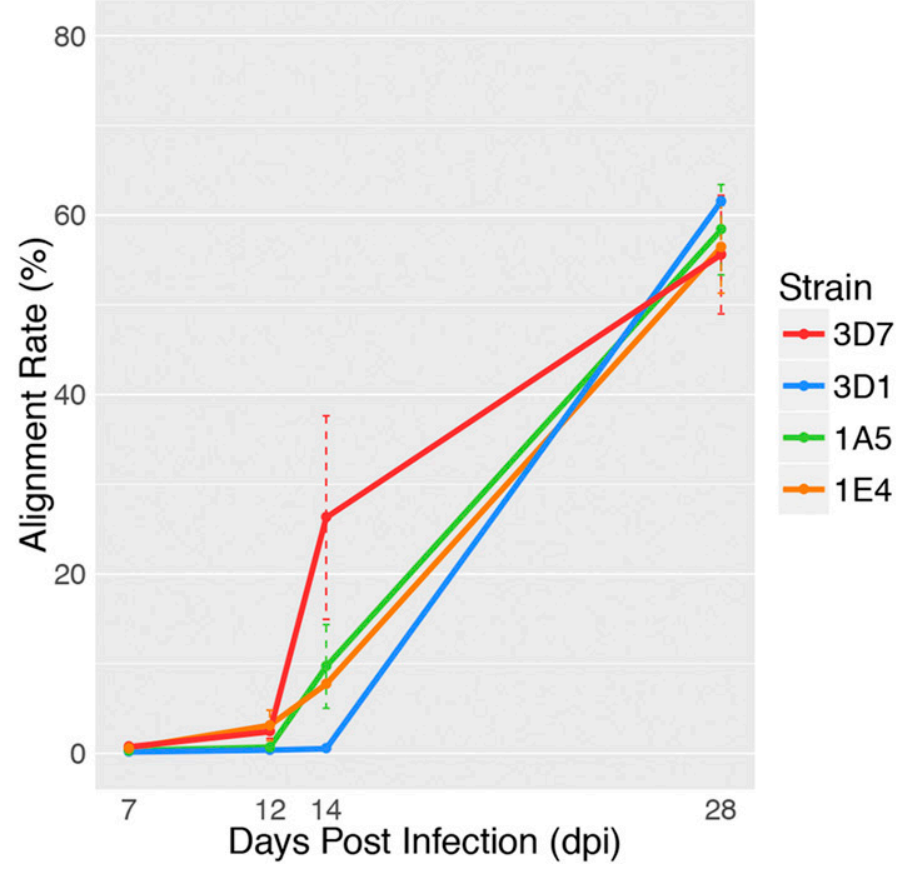

Fig. 1. Disease progression for four analyzed strains of Zymoseptoria tritici. A, Disease symptoms associated with each strain on leaves of wheat cultivar Drifter over time. B, Read alignment rate (percentage of mapped reads to the $Z$. tritici genome) among strains at different time points. Bars indicate standard errors. 
Other SSP-encoding genes with interesting expression profiles were 11_00287 and 5_00002. These genes showed peak expression at $7 \mathrm{dpi}$, suggesting that the corresponding SSPs could play important roles during the asymptomatic phase. Conversely, gene 2_01244 was expressed only during the necrotrophic phase of infection, suggesting that it could play an important role in the transition to necrotrophy (Fig. 2A). The extensive heterogeneity in SSP expression patterns among strains (Fig. 3) illustrates the complexity of the putative effectorome for this pathogen that may partially explain the quantitative inheritance of virulence.

Proteases constitute a group of enzymes that is expanded in the $Z$. tritici genome compared with other fungal plant pathogens. Proteases were proposed to play an important role in nutrient acquisition during the asymptomatic phase of infection (Goodwin et al. 2011) and can also play a defensive role by inactivating pathogenesis-related proteins that are part of a plant's basal defenses to pathogens (Edreva 2005). The expression of secreted proteases was previously proposed to be specific to different stages of infection, showing peak expression at the initiation of the necrotrophic stage (Palma-Guerrero et al. 2016). Here, we show that the expression landscape of 64 predicted proteases (Supplementary Table S2) is very similar among the four strains, with peak expression at $12 \mathrm{dpi}$ for 3D7 and 1E4 and 14 dpi for 1A5 and 3D1 (Supplementary Fig. S3A). The average expression levels at 7 and 12 dpi were much lower for the least virulent strain 3D1 than for the other three strains. Only two protease-encoding genes showed a presence/absence polymorphism among strains, suggesting that this group of proteins is more conserved than the SSPs. The gene encoding aspartyl protease 1_01000 was absent in the 3D7 genome,

Table 1. Overview of the transcriptomic data collected from four Zymoseptoria tritici strains at four time points during the infection cycle

\begin{tabular}{|c|c|c|c|c|c|c|}
\hline \multirow[b]{2}{*}{ Strain } & \multirow[b]{2}{*}{ Infection stage (dpi) } & \multirow[b]{2}{*}{ Library ID } & \multirow[b]{2}{*}{ Replicate } & \multirow[b]{2}{*}{ Total reads (millions) } & \multicolumn{2}{|c|}{ Mapped to the $Z$. tritici genome } \\
\hline & & & & & No. (millions) & Percentage \\
\hline \multirow[t]{13}{*}{ 3D1 } & 7 & 3D1-1-7d & 1 & 107.9 & 0.2 & 0.2 \\
\hline & 7 & $3 D 1-2-7 d$ & 2 & 108.7 & 0.19 & 0.2 \\
\hline & 7 & 3D1-3-7d & 3 & 145.3 & 0.18 & 0.1 \\
\hline & 12 & $3 \mathrm{D} 1-2-12 \mathrm{~d}$ & 1 & 75.8 & 0.27 & 0.4 \\
\hline & 12 & $3 \mathrm{D} 1-5-12 \mathrm{~d}$ & 2 & 58.6 & 0.11 & 0.2 \\
\hline & 12 & $3 \mathrm{D} 1-8-12 \mathrm{~d}$ & 3 & 76.4 & 0.39 & 0.5 \\
\hline & 14 & $3 \mathrm{D} 1-7-14 d$ & 1 & 76.1 & 0.33 & 0.4 \\
\hline & 14 & 3D1-9-14d & 2 & 91.4 & 0.73 & 0.8 \\
\hline & 14 & $3 \mathrm{D} 1-10-14 \mathrm{~d}$ & 3 & 107.2 & 0.39 & 0.4 \\
\hline & 28 & 3D1-1-28d & 1 & 54.2 & 33.7 & 62.1 \\
\hline & 28 & $3 \mathrm{D} 1-4-28 \mathrm{~d}$ & 2 & 47.4 & 29.4 & 61.8 \\
\hline & 28 & $3 D 1-5-28 d$ & 3 & 57.5 & 34.9 & 60.7 \\
\hline & Total & & & $1,006.5$ & 100.79 & \\
\hline \multirow[t]{13}{*}{ 3D7 } & 7 & $3 D 7-2-7 d$ & 1 & 128.9 & 1.07 & 0.8 \\
\hline & 7 & $3 \mathrm{D} 7-8-7 \mathrm{~d}$ & 2 & 158.2 & 1.34 & 0.8 \\
\hline & 7 & $3 \mathrm{D} 7-10-7 \mathrm{~d}$ & 3 & 159.5 & 0.95 & 0.6 \\
\hline & 12 & $3 \mathrm{D} 7-2-12 d$ & 1 & 82.4 & 1.01 & 1.2 \\
\hline & 12 & $3 D 7-3-12 d$ & 2 & 10.4 & 0.4 & 3.8 \\
\hline & 12 & $3 D 7-6-12 d$ & 3 & 61.7 & 1.4 & 2.3 \\
\hline & 14 & $3 \mathrm{D} 7-4-14 d$ & 1 & 105.1 & 23.56 & 22.4 \\
\hline & 14 & 3D7-5-14d & 2 & 63.9 & 5.7 & 8.9 \\
\hline & 14 & $3 \mathrm{D} 7-10-14 \mathrm{~d}$ & 3 & 89.6 & 42.61 & 47.6 \\
\hline & 28 & 3D7-1-28d & 1 & 84.2 & 35.88 & 42.6 \\
\hline & 28 & $3 D 7-5-28 d$ & 2 & 62.2 & 37.43 & 60.1 \\
\hline & 28 & $3 \mathrm{D} 7-10-28 \mathrm{~d}$ & 3 & 52.4 & 33.55 & 64.1 \\
\hline & Total & & & $1,058.5$ & 184.9 & \\
\hline \multirow[t]{13}{*}{$1 \mathrm{E} 4$} & 7 & $1 \mathrm{E} 4-4-7 \mathrm{~d}$ & 1 & 171.7 & 0.89 & 0.5 \\
\hline & 7 & $1 \mathrm{E} 4-5-7 \mathrm{~d}$ & 2 & 144.5 & 0.84 & 0.6 \\
\hline & 7 & $1 E 4-6-7 d$ & 3 & 216.2 & 1.36 & 0.6 \\
\hline & 12 & $1 E 4-3-12 d$ & 1 & 86.9 & 5.68 & 6.5 \\
\hline & 12 & $1 E 4-6-12 d$ & 2 & 69.1 & 0.76 & 1.1 \\
\hline & 12 & $1 \mathrm{E} 4-7-12 d$ & 3 & 59.4 & 1.08 & 1.8 \\
\hline & 14 & $1 \mathrm{E} 4-5-14 \mathrm{~d}$ & 1 & 52.2 & 4.19 & 8 \\
\hline & 14 & $1 \mathrm{E} 4-8-14 \mathrm{~d}$ & 2 & 59.3 & 4.4 & 7.4 \\
\hline & 14 & $1 \mathrm{E} 4-10-14 \mathrm{~d}$ & 3 & 58.5 & 4.56 & 7.8 \\
\hline & 28 & $1 \mathrm{E} 4-3-28 \mathrm{~d}$ & 1 & 69.6 & 46.2 & 66.4 \\
\hline & 28 & $1 \mathrm{E} 4-4-28 \mathrm{~d}$ & 2 & 92.4 & 45.64 & 49.4 \\
\hline & 28 & $1 E 4-6-28 d$ & 3 & 93 & 49.74 & 53.5 \\
\hline & Total & & & $1,172.8$ & 165.34 & \\
\hline \multirow[t]{13}{*}{$1 \mathrm{~A} 5$} & 7 & $1 \mathrm{~A} 5-1-7 \mathrm{~d}$ & 1 & 145.7 & 0.33 & 0.2 \\
\hline & 7 & $1 \mathrm{~A} 5-7-7 \mathrm{~d}$ & 2 & 139.3 & 0.86 & 0.6 \\
\hline & 7 & $1 \mathrm{~A} 5-10-7 \mathrm{~d}$ & 3 & 171.7 & 0.4 & 0.2 \\
\hline & 12 & $1 \mathrm{~A} 5-3-12 \mathrm{~d}$ & 1 & 62.3 & 0.34 & 0.5 \\
\hline & 12 & $1 \mathrm{~A} 5-5-12 \mathrm{~d}$ & 2 & 61.8 & 0.55 & 0.9 \\
\hline & 12 & $1 \mathrm{~A} 5-7-12 \mathrm{~d}$ & 3 & 86.6 & 0.61 & 0.7 \\
\hline & 14 & $1 \mathrm{~A} 5-8-14 \mathrm{~d}$ & 1 & 61.4 & 1.28 & 2.1 \\
\hline & 14 & $1 \mathrm{~A} 5-9-14 \mathrm{~d}$ & 2 & 59.5 & 10.68 & 17.9 \\
\hline & 14 & $1 \mathrm{~A} 5-10-14 \mathrm{~d}$ & 3 & 71.2 & 5.1 & 7.2 \\
\hline & 28 & $1 \mathrm{~A} 5-3-28 \mathrm{~d}$ & 1 & 52.7 & 32.26 & 61.2 \\
\hline & 28 & $1 \mathrm{~A} 5-6-28 \mathrm{~d}$ & 2 & 84.8 & 41.21 & 48.6 \\
\hline & 28 & $1 \mathrm{~A} 5-7-28 \mathrm{~d}$ & 3 & 61.3 & 39.99 & 65.3 \\
\hline & Total & & & $1,058.3$ & 133.61 & \\
\hline
\end{tabular}


while the gene encoding the protease 12_00201 was absent in the $1 \mathrm{~A} 5$ genome. The gene encoding aspartic endopeptidase 1_01089 was not expressed at any time point in any strain, though the gene was present in all four strains, suggesting that this is a pseudogene or it is not expressed during plant infection.

Contrary to proteases, the number of genes encoding PCWDEs is reduced in the $Z$. tritici genome compared with the genomes of other fungal pathogens (do Amaral et al. 2012; Goodwin et al. 2011). The expression of genes encoding PCWDEs in $Z$. tritici is complex and they exhibit life cycle stage-specificity (Brunner et al. 2013). The expression profile of 65 predicted secreted PCWDEs (Supplementary Table S3) was very similar among the four strains (Supplementary Fig. S4A), with a global peak of expression at 14 dpi for all strains except 1E4, which exhibited similar expression at 12 and 14 dpi. As previously reported for 3D7 (Palma-Guerrero et al. 2016), all strains showed lower average expression of PCWDE genes during the asymptomatic stage, with the lowest average expression value obtained for 3D1. Only one gene encoding a secreted PCWDE, 4_00053 (glycoside hydrolase family 32), showed a presence/ absence polymorphism among strains, being absent from the 1A5 genome. All other genes encoding PCWDEs were present in the genome of the four strains, even though some of them were not expressed in some strains at any time point. The expression peak of PCWDE genes during the necrotrophic stage suggests that these enzymes play a key role in the induction of necrosis, likely through degrading plant cell walls to release nutrients needed for fungal metabolism.

Secreted lipases can contribute to virulence in addition to their roles in lipid and fatty acid degradation (Subramoni et al. 2010). The expression profiles of the 29 predicted secreted lipases (Supplementary Table S4) were very similar among the four strains (Supplementary Fig. S5A), showing global peak expression very similar to the PCWDEs at $14 \mathrm{dpi}$. Again, 3D1 had the lowest global expression values at 7 dpi. All 29 genes were conserved among strains. The high similarity in transcription profiles for secreted PCWDEs and secreted lipases suggests that gene expression is synchronized for these groups of hydrolytic enzymes (Palma-Guerrero et al. 2016), with peak expression during the necrotrophic stage enabling the pathogen to rapidly mobilize plant lipids released from the dying plant cells to use for its own metabolism.

Secreted peroxidases are highly up-regulated during the asymptomatic phase between 3 and 7 dpi (Palma-Guerrero et al. 2016). Of the 18 secreted peroxidases annotated in $Z$. tritici reference strain IPO323, 15 are chloroperoxidases, an expanded protein family in the Mycosphaerellaceae (do Amaral et al. 2012). All 18 genes were conserved in the genomes of the four strains (Supplementary Fig. S6A). The transcription profiles for all 18 genes were similar across all four strains (Supplementary Table S5). As reported earlier (Palma-Guerrero et al. 2016), the peak of expression for secreted peroxidases was at 7 dpi for 3D7, with a steady decrease in expression during the infection cycle. The same pattern was found for 1A5 and 1E4, while the least virulent strain, 3D1, showed lower expression values at 7 and $12 \mathrm{dpi}$. These expression patterns suggest that peroxidases may contribute to the early establishment of the pathogen in the plant, either by protecting the pathogen from reactive oxygen species produced by the plant or via the production or modification of secondary metabolites (Neumann et al. 2008).

The lower expression values at the early stages of infection for all the secreted enzymes in the 3D1 strain may be partially responsible for the lower virulence and the longer latent period observed for this strain. But these lower expression values may also be a consequence of the prolonged latency of the 3D1 strain.
The genomes of plant-pathogenic fungi carry many secondary metabolite gene clusters responsible for the biosynthesis of pigments (e.g., melanin) and toxins (e.g., fumonisin) important for virulence and nutrient acquisition (Howlett 2006; Keller
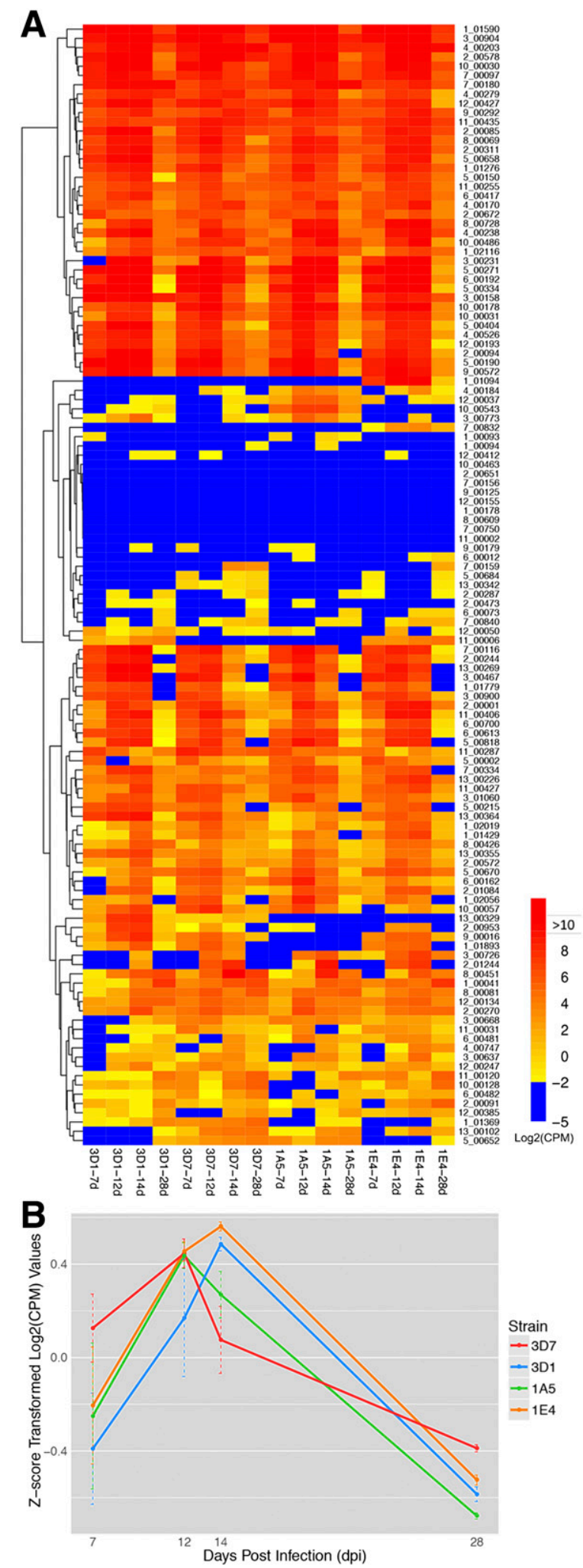

Fig. 2. Small secreted protein (SSP) transcription profiles associated with four strains of Zymoseptoria tritici. A, Heatmap showing expression values for 121 SSPs across the infection cycle. B, Graphical representation of the average expression ( $Z$ score transformed $\log _{2}$ counts per million values) per time point among strains. Bars indicate standard errors. 


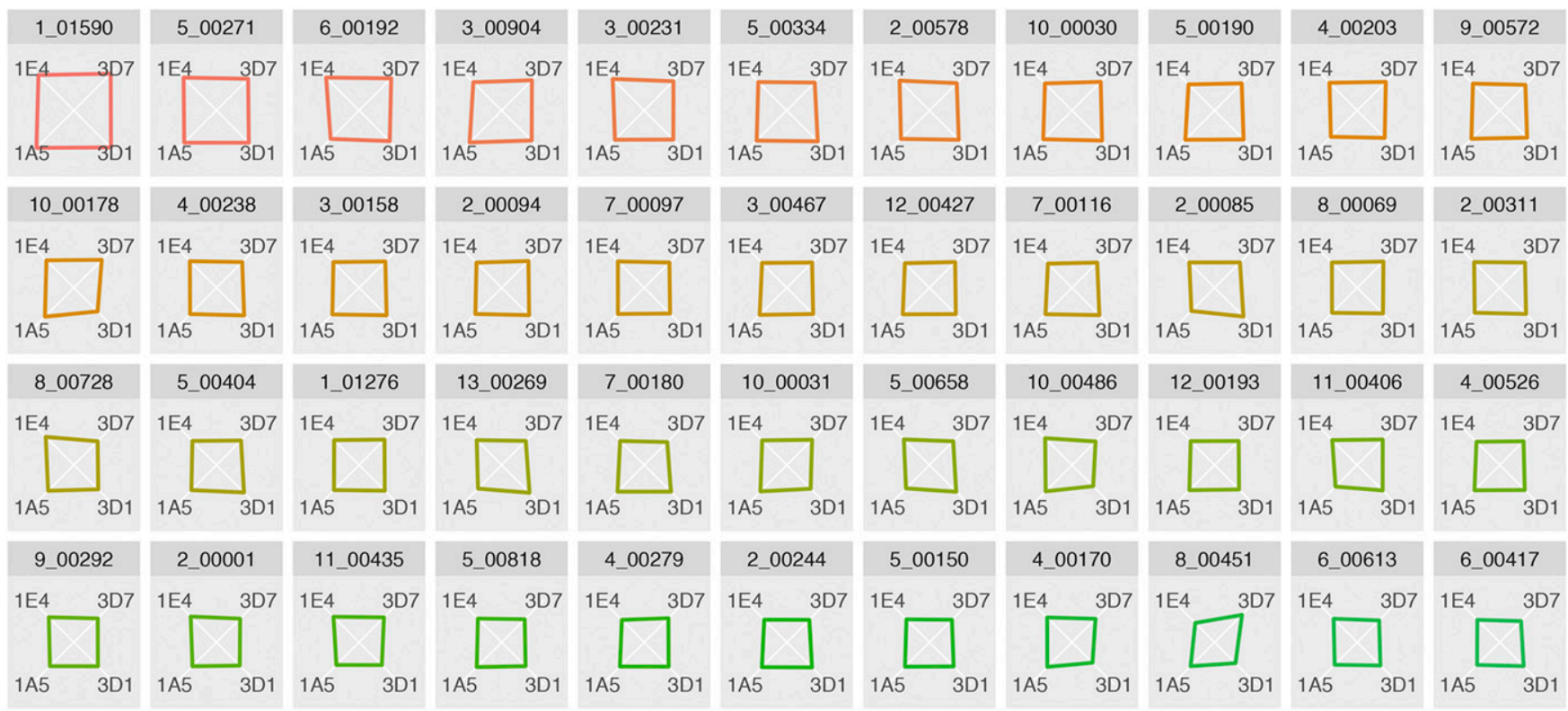

\begin{tabular}{|l|l|l|l|l|l|l|l|||}
\hline $11 \_00255$ & $1 \_02116$ & 3_00900 & $6 \_00700$ & $11 \_00287$ & 2_00672 & 1_00041 & 2_01244 \\
\hline
\end{tabular}

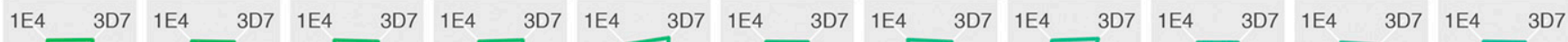
$\square+\square$

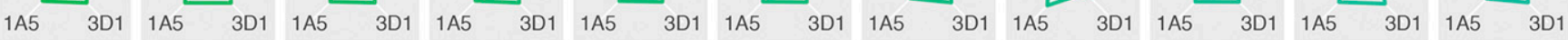

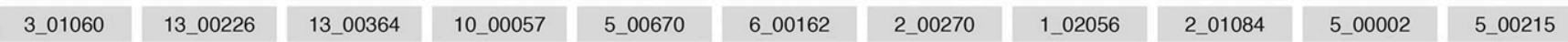
$\begin{array}{lllllllllllllllllllllll}1 \mathrm{E} 4 & 3 \mathrm{D} 7 & 1 \mathrm{E} 4 & 3 \mathrm{D} 7 & 1 \mathrm{E} 4 & 3 \mathrm{D} 7 & 1 \mathrm{E} 4 & 3 \mathrm{D} 7 & 1 \mathrm{E} 4 & 3 \mathrm{D} 7 & 1 \mathrm{E} 4 & 3 \mathrm{D} 7 & 1 \mathrm{E} 4 & 3 \mathrm{D} 7 & 1 \mathrm{E} 4 & 3 \mathrm{D} 7 & 1 \mathrm{E} 4 & 3 \mathrm{D} 7 & 1 \mathrm{E} 4 & 3 \mathrm{D} 7 & 1 \mathrm{E} 4 & 3 \mathrm{D} 7\end{array}$

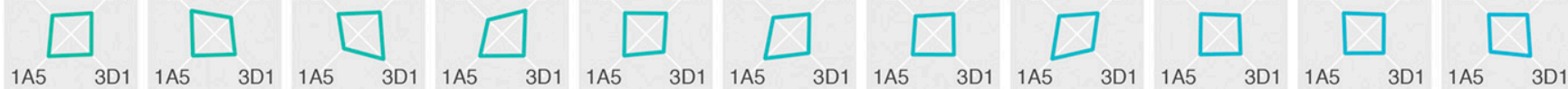

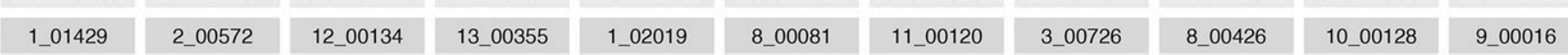
$\begin{array}{llllllllllllllllllllll}1 \mathrm{E} 4 & 3 \mathrm{D} 7 & 1 \mathrm{E} 4 & 3 \mathrm{D} 7 & 1 \mathrm{E} 4 & 3 \mathrm{D} 7 & 1 \mathrm{E} 4 & 3 \mathrm{D} 7 & 1 \mathrm{E} 4 & 3 \mathrm{D} 7 & 1 \mathrm{E} 4 & 3 \mathrm{D} 7 & 1 \mathrm{E} 4 & 3 \mathrm{D} 7 & 1 \mathrm{E} 4 & 3 \mathrm{D} 7 & 1 \mathrm{E} 4 & 3 \mathrm{D} 7 & 1 \mathrm{E} 4 & 3 \mathrm{D} 7 & 1 \mathrm{E} 4 & 3 \mathrm{D} 7\end{array}$

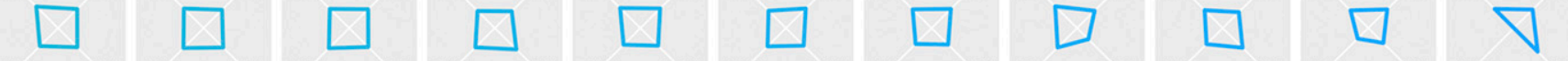
$\begin{array}{llllllllllllllllllllllllllll}\text { AA5 } & 3 \mathrm{D} 1 & 1 \mathrm{~A} 5 & 3 \mathrm{D} 1 & 1 \mathrm{~A} 5 & 3 \mathrm{D} 1 & 1 \mathrm{~A} 5 & 3 \mathrm{D} 1 & 1 \mathrm{~A} 5 & 3 \mathrm{D} 1 & 1 \mathrm{~A} 5 & 3 \mathrm{D} 1 & 1 \mathrm{~A} 5 & 3 \mathrm{D} 1 & 1 \mathrm{~A} 5 & 3 \mathrm{D} 1 & 1 \mathrm{~A} 5 & 3 \mathrm{D} 1 & 1 \mathrm{~A} 5 & 3 \mathrm{D} 1 & 1 \mathrm{~A} 5 & 3 \mathrm{D} 1\end{array}$

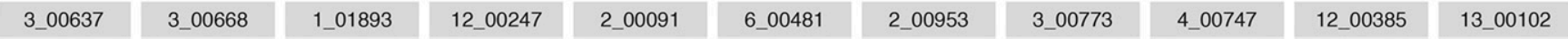
$\begin{array}{llllllllllllllllllllllll}1 \mathrm{E} 4 & 3 \mathrm{D} 7 & 1 \mathrm{E} 4 & 3 \mathrm{D} 7 & 1 \mathrm{E} 4 & 3 \mathrm{D} 7 & 1 \mathrm{E} 4 & 3 \mathrm{D} 7 & 1 \mathrm{E} 4 & 3 \mathrm{D} 7 & 1 \mathrm{E} 4 & 3 \mathrm{D} 7 & 1 \mathrm{E} 4 & 3 \mathrm{D} 7 & 1 \mathrm{E} 4 & 3 \mathrm{D} 7 & 1 \mathrm{E} 4 & 3 \mathrm{D} 7 & 1 \mathrm{E} 4 & 3 \mathrm{D} 7 & 1 \mathrm{E} 4 & 3 \mathrm{D} 7\end{array}$

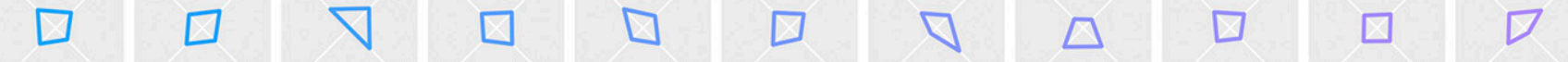
$\begin{array}{llllllllllllllllllllllll}1 A 5 & 3 D 1 & 1 A 5 & 3 D 1 & 1 A 5 & 3 D 1 & 1 A 5 & 3 D 1 & 1 A 5 & 3 D 1 & 1 A 5 & 3 D 1 & 1 A 5 & 3 D 1 & 1 A 5 & 3 D 1 & 1 A 5 & 3 D 1 & 1 A 5 & 3 D 1 & 1 A 5 & 3 D 1\end{array}$

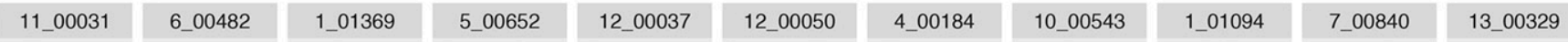
$\begin{array}{lllllllllllllllllllllll}1 \mathrm{E} 4 & 3 \mathrm{D} 7 & 1 \mathrm{E} 4 & 3 \mathrm{D} 7 & 1 \mathrm{E} 4 & 3 \mathrm{D} 7 & 1 \mathrm{E} 4 & 3 \mathrm{D} 7 & 1 \mathrm{E} 4 & 3 \mathrm{D} 7 & 1 \mathrm{E} 4 & 3 \mathrm{D} 7 & 1 \mathrm{E} 4 & 3 \mathrm{D} 7 & 1 \mathrm{E} 4 & 3 \mathrm{D} 7 & 1 \mathrm{E} 4 & 3 \mathrm{D} 7 & 1 \mathrm{E} 4 & 3 \mathrm{D} 7 & 1 \mathrm{E} 4 & 3 \mathrm{D} 7\end{array}$ D $\square \square \square \square \square$

$\begin{array}{llllllllllllllllllllllll}\text { AA5 } & 3 \mathrm{D} 1 & 1 \mathrm{~A} 5 & 3 \mathrm{D} 1 & 1 \mathrm{~A} 5 & 3 \mathrm{D} 1 & 1 \mathrm{~A} 5 & 3 \mathrm{D} 1 & 1 \mathrm{~A} 5 & 3 \mathrm{D} 1 & 1 \mathrm{~A} 5 & 3 \mathrm{D} 1 & 1 \mathrm{~A} 5 & 3 \mathrm{D} 1 & 1 \mathrm{~A} 5 & 3 \mathrm{D} 1 & 1 \mathrm{~A} 5 & 3 \mathrm{D} 1 & 1 \mathrm{~A} 5 & 3 \mathrm{D} 1 & 1 \mathrm{~A} 5 & 3 \mathrm{D} 1\end{array}$

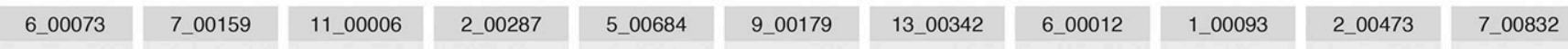
$\begin{array}{lllllllllllllllllllllll}1 \mathrm{E} 4 & 3 \mathrm{D} 7 & 1 \mathrm{E} 4 & 3 \mathrm{D} 7 & 1 \mathrm{E} 4 & 3 \mathrm{D} 7 & 1 \mathrm{E} 4 & 3 \mathrm{D} 7 & 1 \mathrm{E} 4 & 3 \mathrm{D} 7 & 1 \mathrm{E} 4 & 3 \mathrm{D} 7 & 1 \mathrm{E} 4 & 3 \mathrm{D} 7 & 1 \mathrm{E} 4 & 3 \mathrm{D} 7 & 1 \mathrm{E} 4 & 3 \mathrm{D} 7 & 1 \mathrm{E} 4 & 3 \mathrm{D} 7 & 1 \mathrm{E} 4 & 3 \mathrm{D} 7\end{array}$

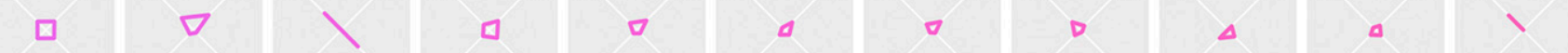
$\begin{array}{llllllllllllllllllllllll}1 A 5 & 3 D 1 & 1 A 5 & 3 D 1 & 1 A 5 & 3 D 1 & 1 A 5 & 3 D 1 & 1 A 5 & 3 D 1 & 1 A 5 & 3 D 1 & 1 A 5 & 3 D 1 & 1 A 5 & 3 D 1 & 1 A 5 & 3 D 1 & 1 A 5 & 3 D 1 & 1 A 5 & 3 D 1\end{array}$

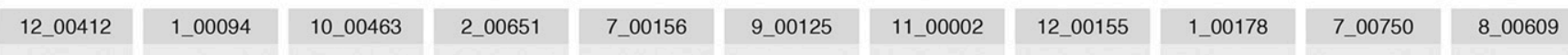
$\begin{array}{lllllllllllllllllllllllllll}1 \mathrm{E} 4 & 3 \mathrm{D} 7 & 1 \mathrm{E} 4 & 3 \mathrm{D} 7 & 1 \mathrm{E} 4 & 3 \mathrm{D} 7 & 1 \mathrm{E} 4 & 3 \mathrm{D} 7 & 1 \mathrm{E} 4 & 3 \mathrm{D} 7 & 1 \mathrm{E} 4 & 3 \mathrm{D} 7 & 1 \mathrm{E} 4 & 3 \mathrm{D} 7 & 1 \mathrm{E} 4 & 3 \mathrm{D} 7 & 1 \mathrm{E} 4 & 3 \mathrm{D} 7 & 1 \mathrm{E} 4 & 3 \mathrm{D} 7 & 1 \mathrm{E} 4 & 3 \mathrm{D} 7\end{array}$ $\begin{array}{llllllllllllllllllllll}1 \mathrm{~A} 5 & 3 \mathrm{D} 1 & 1 \mathrm{~A} 5 & 3 \mathrm{D} 1 & 1 \mathrm{~A} 5 & 3 \mathrm{D} 1 & 1 \mathrm{~A} 5 & 3 \mathrm{D} 1 & 1 \mathrm{~A} 5 & 3 \mathrm{D} 1 & 1 \mathrm{~A} 5 & 3 \mathrm{D} 1 & 1 \mathrm{~A} 5 & 3 \mathrm{D} 1 & 1 \mathrm{~A} 5 & 3 \mathrm{D} 1 & 1 \mathrm{~A} 5 & 3 \mathrm{D} 1 & 1 \mathrm{~A} 5 & 3 \mathrm{D} 1 & 1 \mathrm{~A} 5 & 3 \mathrm{D} 1\end{array}$

Fig. 3. Among strain comparison of maximum expression values associated with 121 small secreted proteins in Zymoseptoria tritici. Values are TMM (trimmed mean of $\mathrm{M}) \log _{2}$ (counts per million) values. The shape of each radar diagram indicate how homogeneous the maximum expression values are among strains (squares indicate similar expression values among strains, whereas triangles or lines indicate lower [or absent] expression for some strains), the size of the diagram indicates the magnitude of gene expression, and the color of each radar indicates the similarity in the figure area among different genes. 
et al. 2005). Most secondary metabolites are produced using either nonribosomal peptide synthetases or PKSs in multistep biosynthetic pathways encoded by gene clusters organized around the synthase genes (Brakhage 2013). A large proportion of fungal secondary metabolites result from iterative type I PKSs (Cox and Simpson 2009). The Z. tritici reference genome contains nine predicted type I PKS genes (Goodwin et al. 2011; Ohm et al. 2012) that we included in our analysis (Fig. 4). PKS1 showed peak expression at 14 and at 28 dpi for three of the strains, while 3D1 showed peak expression at $12 \mathrm{dpi}$. PKS1 had significantly lower expression (false discovery rate [FDR] $\leq$ 0.05 ) at day 28 in 3D1 and 1A5 compared with 3D7 and 1E4 (Fig. 4). PKS1 is known to catalyze the first step of DHN melanin biosynthesis (Butler and Day 1998) and melanin production is expected to increase during the formation of the highly melanized pycnidia (Eyal et al. 1987). The lower expression of $P K S 1$ in $3 \mathrm{D} 1$ and $1 \mathrm{~A} 5$ at day 28 could be associated with the smaller number of pycnidia produced by these two strains compared with 3D7 and 1E4 (Fig. 1A) (Stewart et al. 2017). PKS2 showed similar expression among strains and time points. The $P K S 3$ peak of expression was at 7 dpi for all strains (Fig. 4), suggesting that the unknown secondary metabolite produced by this cluster may contribute to the establishment of the fungus in the plant. $P K S 9$ showed a similar pattern of expression but only in strains 3D7 and 1E4 (Fig. 4). Analyses of gene presence or absence showed that this gene is absent in the genomes of 3D1 and 1A5, indicating that these strains could not produce the corresponding secondary metabolite. PKS4 showed peak expression at $14 \mathrm{dpi}$ (Fig. 4), suggesting that it plays a role during the necrotrophic stage. Expression was significantly lower $(F D R \leq 0.05)$ in the least virulent strain, 3D1, compared with the other three strains at both 12 and 14 dpi. Similarly, PKS5 expression peaked at $14 \mathrm{dpi}$ in the four strains. It was significantly up-regulated (FDR $\leq 0.05)$ at $14 \mathrm{dpi}$ in 1E4 compared with the other three strains (Fig. 4). Both PKS7 and $P K S 8$ showed peak expression at $12 \mathrm{dpi}$, but for $3 \mathrm{D} 1$, the expression of $P K S 7$ was still high at $14 \mathrm{dpi}$, whereas for the other three strains it dropped, which could be associated with the slower progress of infection for this strain (Fig. 4). The peak of expression preceding the first visual symptoms for both

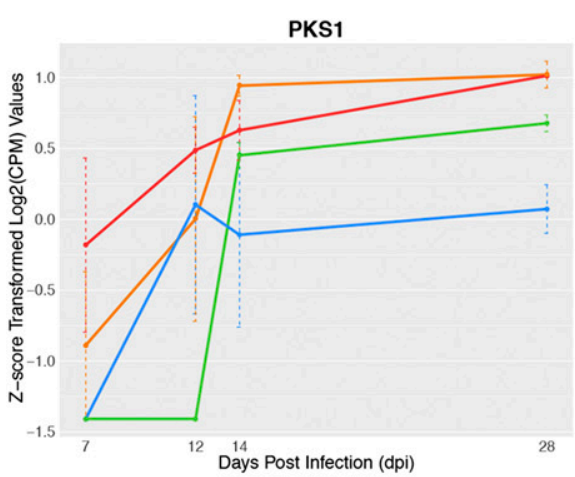

PKS4

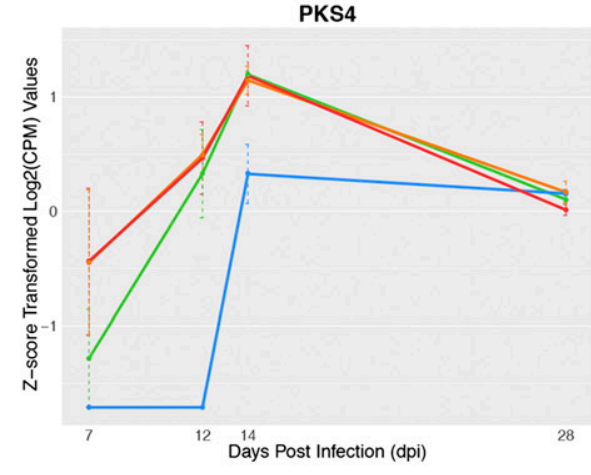

PKS8

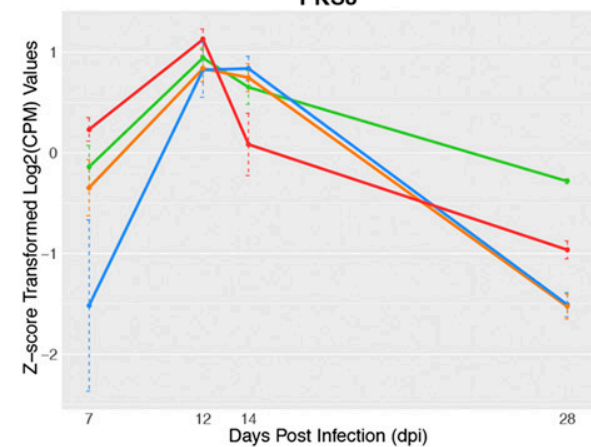

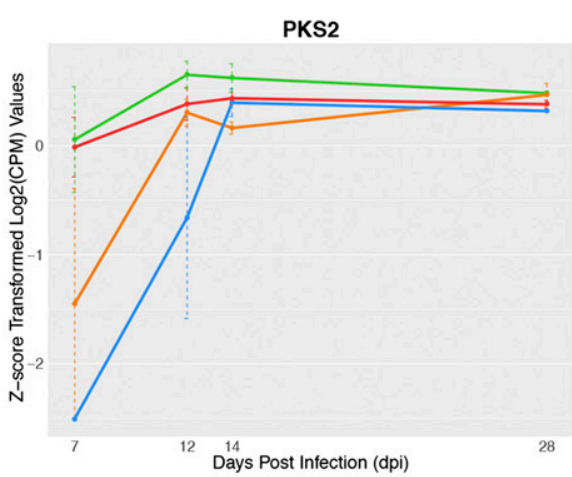

PKS5

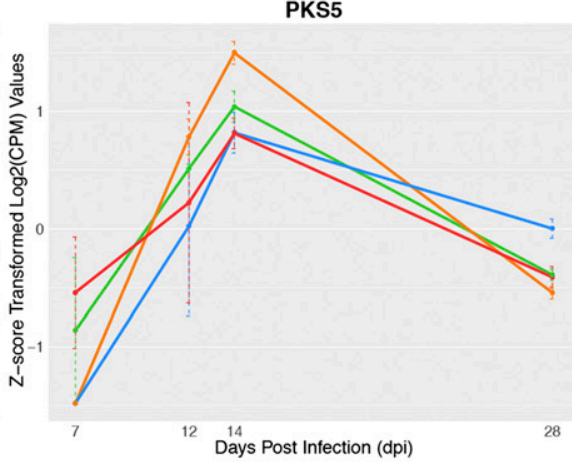

PKS9

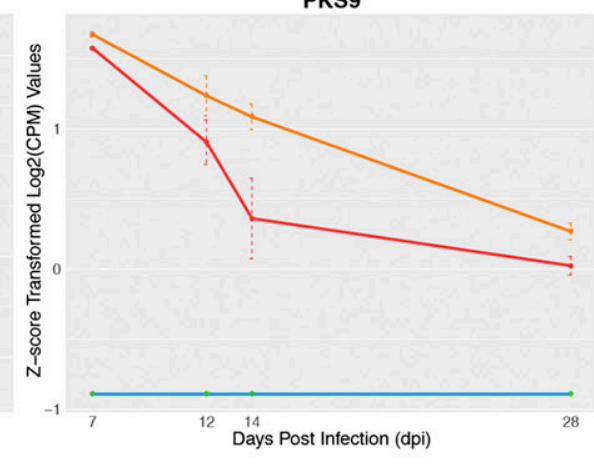

$3 \mathrm{D} 1$

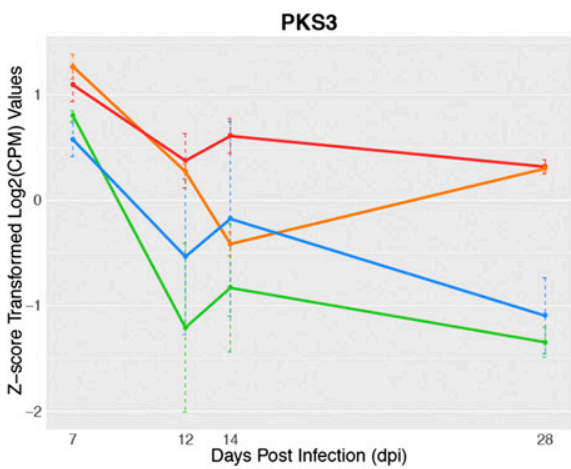

PKS7

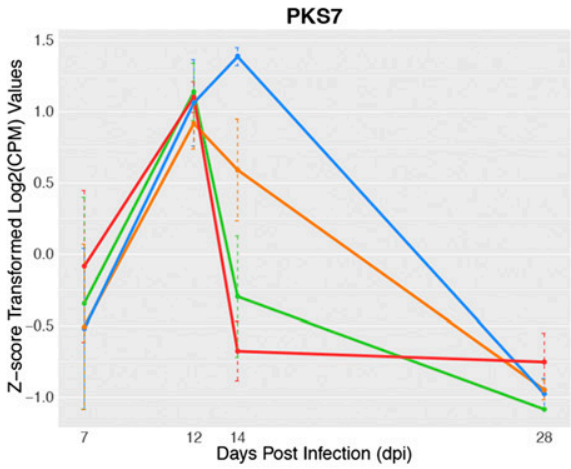

PKS10

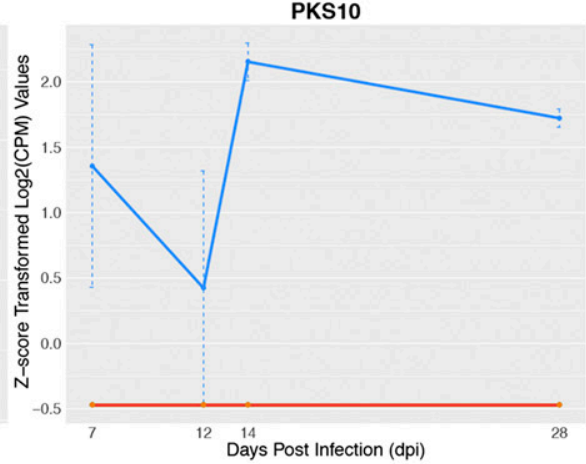

\section{E4}

Fig. 4. Expression profiles of nine polyketide synthase (PKS) genes in four strains of Zymoseptoria tritici. Values shown are $Z$ score transformed TMM (trimmed mean of $\mathrm{M}$ ) $\log _{2}$ (counts per million) values. Bars indicate standard errors. 
PKS7 and PKS8 suggests that both genes play a role during the transition to necrotrophy. Finally, $P K S 10$ was similarly expressed at all time points but only in 3D1. Analyses of gene presence or absence confirmed that $P K S 10$ was present only in the 3D1 genome.

Our detailed analyses of PKSs revealed significant differences in their expression profiles among strains, resulting from a combination of presence/absence polymorphisms and varying levels of expression during the infection cycle. The finding that some PKSs exhibit peak expression during the transition phase or the necrotrophic phase suggests that several of the corresponding secondary metabolites may act as phytotoxins that contribute to plant cell death or as antimicrobial compounds that protect the food supply released by the dying plant cells from other microorganisms. However, it appears that $P K S 3$ and $P K S 9$ are more likely to be involved in helping the fungus to establish inside the plant during the early asymptomatic stages of infection.

\section{Conserved infection transcriptome among strains.}

To better define the core Z. tritici infection transcriptome, we identified the most highly expressed genes $(>1,000$ trimmed mean of $\mathrm{M}$ [TMM] normalized reads per kilobase of transcript per million mapped reads [RPKM]) shared among all strains at each time point. Sixteen of the 140 genes meeting these criteria at 7 dpi (Fig. 5A and Supplementary Table S6) encode secreted hypothetical or predicted proteins lacking functional annotations; seven of these are SSPs. An especially interesting gene encodes a protease inhibitor i9 (10_00277), which had the highest expression at day 28 (Fig. 5E). Genes in this family are known to inhibit subtilisin proteases in Pleurotus ostreatus and Saccharomyces cerevisiae (Dunaevsky et al. 2014). Gene 10_00277 doesn't have a signal peptide, but it is predicted to be secreted via the nonclassical secretory pathway, according to SecretomeP (Bendtsen et al. 2004). This protease inhibitor could be either inhibiting proteases from the host (Mueller et al. 2013) or inhibiting proteases from competing microbes (Kim et al. 2009). The peak of expression at $28 \mathrm{dpi}$, when the fungus is growing on dead plant tissue, suggests that its role is not associated with the inhibition of host proteases. We speculate that this protease inhibitor has antimicrobial properties that exclude or suppress other microbes competing for nutrients released during the necrotrophic and saprotrophic stages of infection.

At 12 dpi, 171 genes were highly expressed in all strains (Fig. 5B; Supplementary Table S7). Of these genes, 44 encoded hypothetical or predicted proteins without functional annotations, 24 genes encoded SSPs, and two genes encoded LysM effectors, i.e., Mg3LysM (11_00155) and MgXLysM (8_00412) (Marshall et al. 2011). Both genes encoding LysM effectors were highly expressed from day 7 to day 14 for all strains (Fig. 5F and G). The discovery of LysM effectors among the most highly expressed genes across all strains during the transition to necrotrophy supports the hypothesis that other genes on this list also encode core virulence functions of $Z$. tritici, though functional studies will be needed to confirm this hypothesis.

At day 14, 109 genes were highly expressed in all strains (Fig. 5C; Supplementary Table S8). Of these genes, 22 encoded hypothetical or predicted proteins without functional annotations and 10 encoded SSPs that could play a role in necrosis; 54 genes encoded ribosomal proteins, consistent with the rapid growth in pathogen biomass occurring during the necrotrophic phase of the disease cycle.

In all strains, 212 genes were highly expressed at day 28 (Fig. 5D; Supplementary Table S9). There were no SSPs on this list and 68 of the genes encoded ribosomal proteins, consistent with the mainly saprotrophic growth occurring during this phase of the infection cycle. The high expression of two genes encoding heat shock proteins suggests that the fungus may be encountering some stress due to the decreased availability of nutrients at this late stage of infection.

\section{Identification of new virulence gene candidates based on differential gene expression among strains.}

We identified differentially expressed genes based on pairwise comparisons among strains of gene expression at the same time point of the infection cycle, using the FDR threshold of 0.05 and a $\log _{2}$ fold change of 1 . Using these criteria, approximately 20 to $30 \%$ of the genome was differentially regulated among the strains, illustrating that transcriptomes can differ significantly among strains, even while infecting the same host genotype and growing in the same environmental conditions. Most of the differentially expressed genes were located on core chromosomes (Fig. 6A), but 5 to $7 \%$ of differentially expressed genes were located on accessory chromosomes (Fig. 6B). The highest degrees of differential expression were observed at 14 and 28 dpi (Fig. 6C to F; Supplementary Table S10). The high number of differentially expressed genes at 14 dpi can be explained mainly by the asynchronicity of the infection process among strains. A good example of this is the comparison of 3D1 and 3D7, which shows 3D1 is still asymptomatic at 14 dpi whereas 3D7 is already in the necrotrophic stage (Fig. 1A). We consider it more notable that 11 to $16 \%$ of genes were differentially expressed at $28 \mathrm{dpi}$, because we expected the saprotrophic stage would be the least variable stage of the infection cycle. All strains showed a similar read alignment rate at this stage (Fig. 1B), suggesting a similar fungal biomass for all four strains. During saprotrophy, all strains are growing on dead leaves (Fig. 1A) and rapidly converting leaf biomass to fungal biomass while actively growing and producing reproductive structures. A Gene Ontology (GO) enrichment analysis of the six pairwise comparisons among strains showed that the most enriched GO categories at 28 dpi were genes involved in carbohydrate metabolism, lipid metabolism, alcohol metabolism, and oxidoreduction (Supplementary Figs. S7 to S12), suggesting significant metabolic differences among strains during their digestion of the dead plant tissue.

We used the asynchronicity of infection and the differential expression among strains at 7 and 12 dpi to identify genes that may explain differences in virulence among strains. A focus on these early stages of the infection cycle enabled us to identify candidate genes associated with differences in latent periods. We examined all genes differentially upregulated in 3D7 compared with the other three strains at both time points. Among the 23 genes differentially upregulated in 3D7 at $7 \mathrm{dpi}$, most encoded hypothetical proteins without a functional annotation, but two genes had annotations that could affect virulence, including a hydrophobin (9_00020) and a homolog of the transcription factor LaeA (1_00348). Further analysis of the expression profiles of both genes across different time points allowed us to dismiss the possibility that their delayed expression was a consequence of asynchronicity, because both genes had lower expression across all time points assessed for the other three strains (Fig. 7A). Hydrophobins are involved in the interaction of pathogenic fungi with the hydrophobic leaf surface and have been associated with fungal virulence, but it is not understood how they affect virulence (Bayry et al. 2012). We hypothesize that the higher expression of 9_00020 in the most virulent strain contributes to its higher virulence. Future functional studies will test this hypothesis. The intergenic region upstream of 9_00020 was highly polymorphic among the four strains, possibly affecting transcription-factor binding sites that could explain the differences in gene expression. LaeA is a 
transcriptional regulator of secondary metabolite gene clusters in Aspergillus nidulans and Aspergillus fumigatus (Bok and Keller 2004; Bok et al. 2005). LaeA may play a similar role in Z. tritici. The intergenic region upstream of the LaeA homolog 1_00348 shows high sequence variation among the four strains, including small insertions and deletions, which could affect $c i s$ regulatory elements in the promoter region that affects LaeA expression.
The comparison at 12 dpi identified 21 genes significantly upregulated in 3D7 compared with the other three strains. Most of these genes encoded hypothetical proteins without functional annotations, but four genes had annotations that may be associated with virulence (Fig. 7B). All four genes had high expression at 7 and $12 \mathrm{dpi}$, suggesting an important role during the asymptomatic phase. The gene encoding hydrophobin 9_00020 was also found at $7 \mathrm{dpi}$. The other three genes encoded a

\section{Day 7}

A
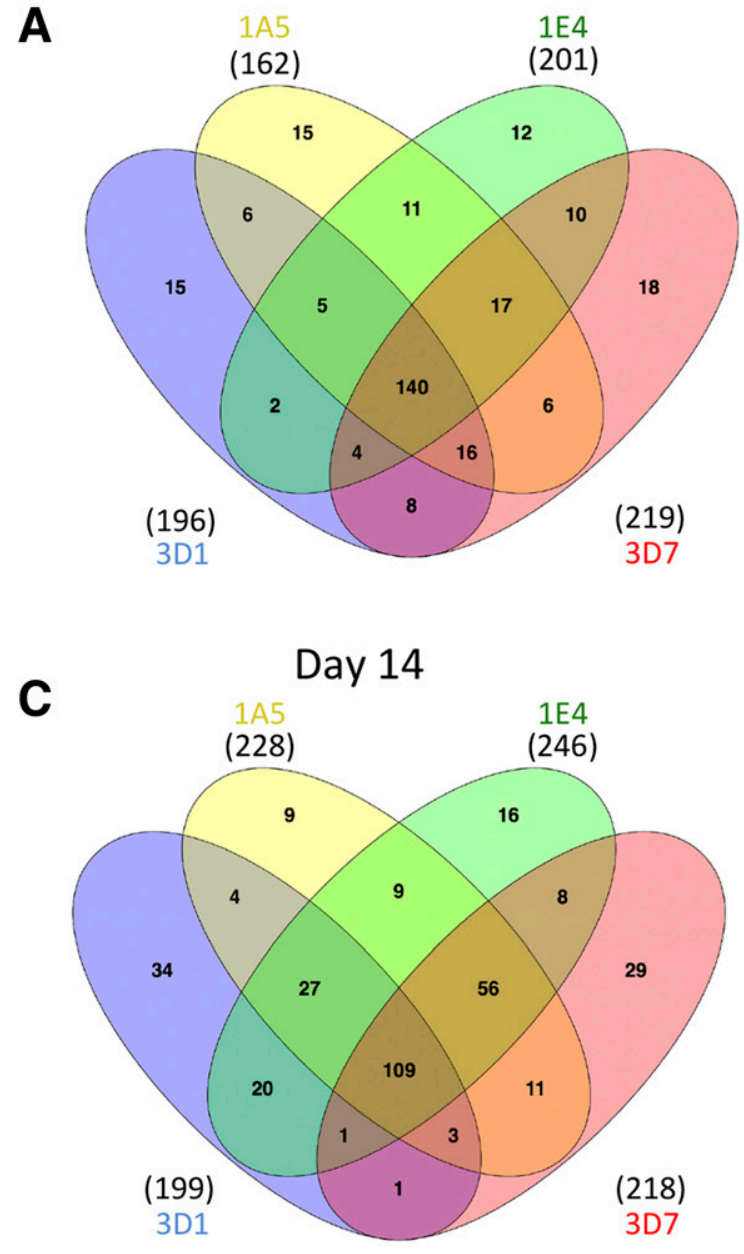

Day 12

B
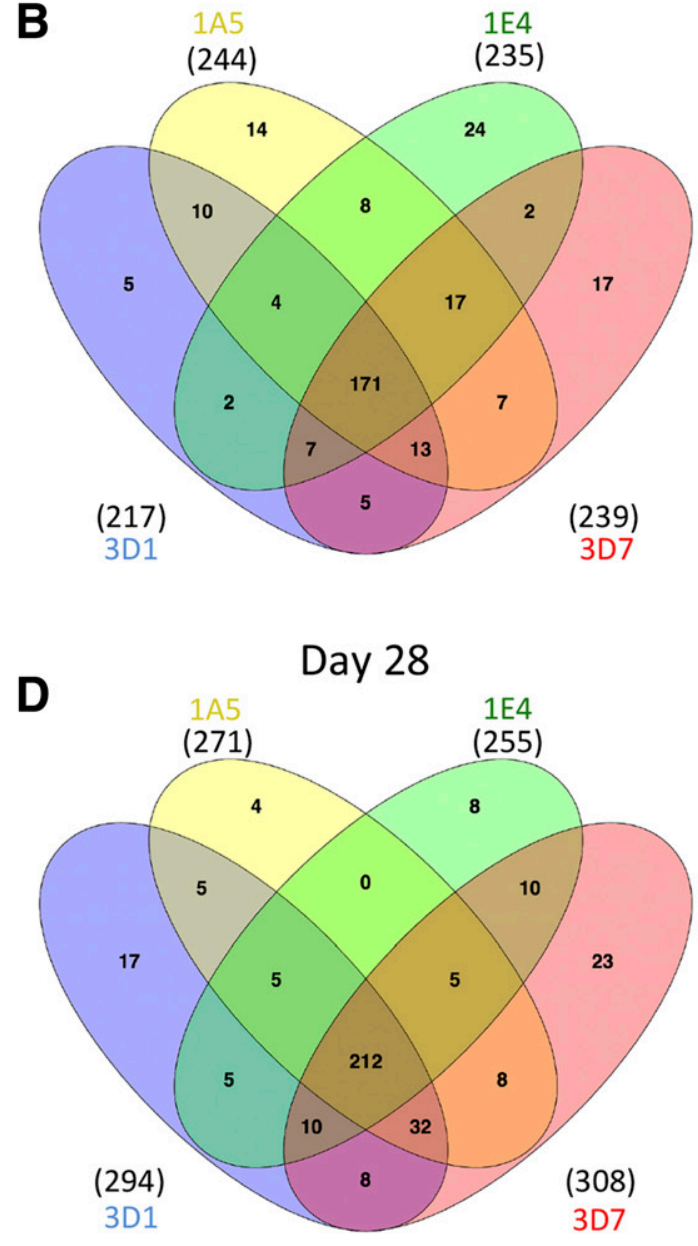

E

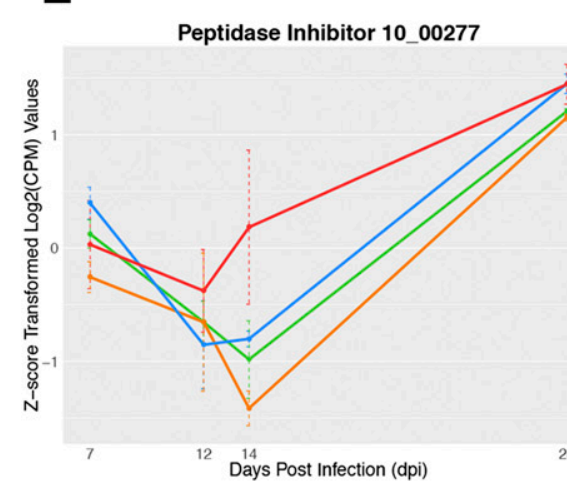

$\mathbf{F}$

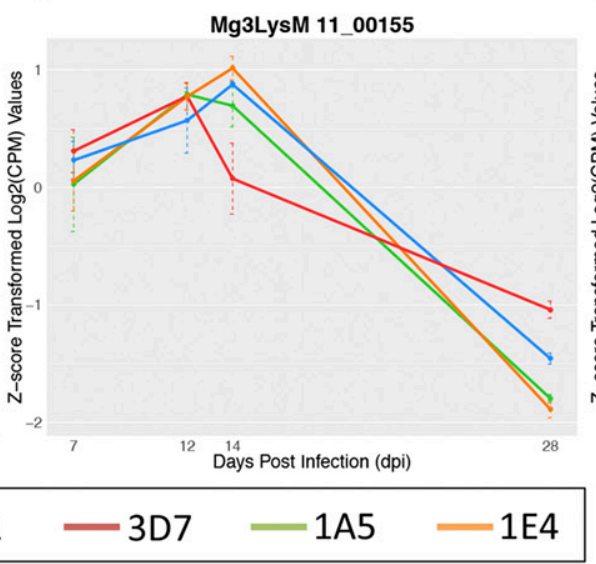

$$
-3 \mathrm{D} 1-3 \mathrm{D} 7 \quad-1 \mathrm{~A} 5-1 \mathrm{E} 4
$$

G

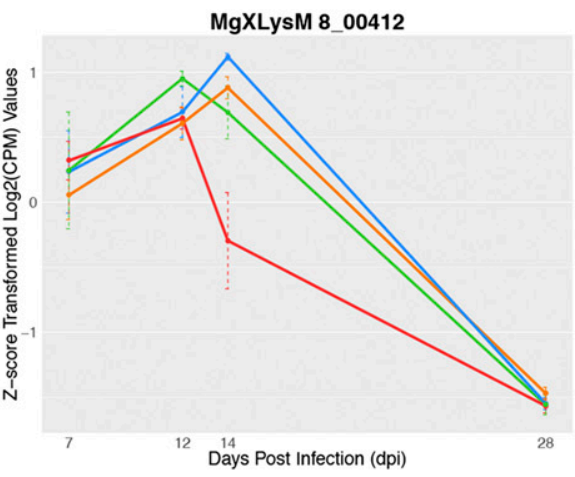

Fig. 5. Core Zymoseptoria tritici virulence transcriptome. A to D, Venn diagrams of the most highly expressed ( $>1,000$ trimmed mean of $\mathbf{M}$ reads per kilobase of transcript per million mapped reads) genes in each strain at different time points. $\mathbf{E}$ to $\mathbf{G}$, Expression profiles of selected genes hypothesized to affect quantitative virulence. Bars indicate standard errors. 
secreted chloroperoxidase (7_00761), another chloroperoxidase (11_00289) that is predicted to be secreted via a nonclassical pathway, according to SecretomeP (Bendtsen et al. 2004), and a SSP (1_02089) with $4.9 \%$ cysteines. All four genes showed low expression in 3D1, 1A5, and 1E4 at all time points (Fig. 7B). We hypothesize that the high expression of secreted chloroperoxidases in 3D7 helps it to become established in the plant during early stages of infection. The intergenic regions upstream of both 7_00761 and 11_00289 were highly variable among the four strains.

\section{Conclusions.}

We present the first intraspecific comparative transcriptome analysis of a fungal plant pathogen under common garden conditions, encompassing an entire infection cycle and including four $Z$. tritici strains differing in virulence on wheat. We found conserved transcription profiles among strains for some genes involved in virulence, including proteases, PCWDEs, and lipases, but significant differences in expression for many other genes, including SSPs and secreted peroxidases. We propose that heterogeneity in the transcriptome could explain a significant portion of the quantitative differences in virulence observed within this species (Stewart et al. 2017; Zhan et al. 2002, 2005). Polymorphisms in intergenic regions upstream of the differentially expressed genes could explain many of the differences in expression. In addition, comparative transcriptomic analyses identified several candidate genes that may
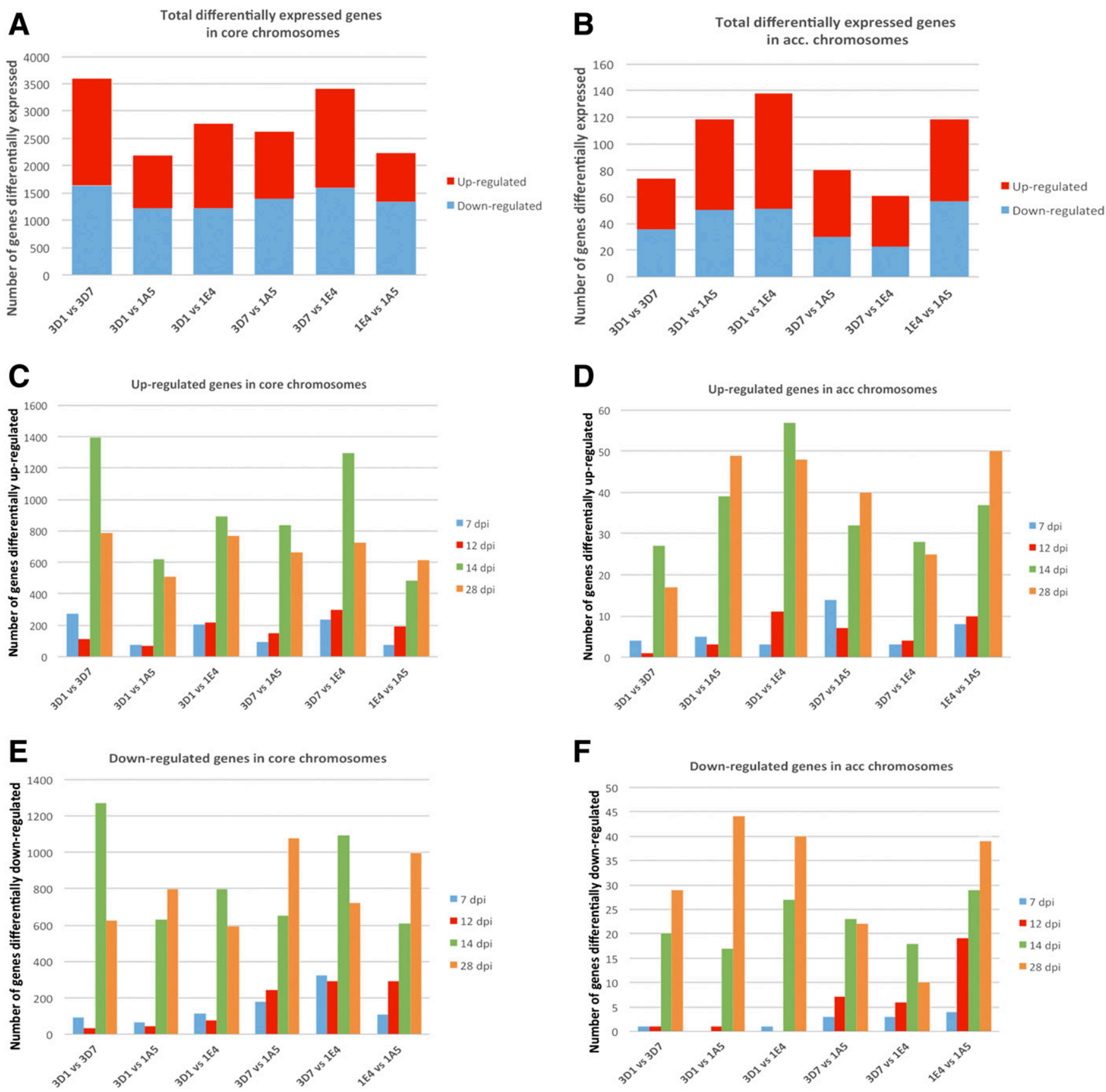

Fig. 6. Differentially expressed genes among strains of Zymoseptoria tritici. A, Total number of differentially expressed genes from core chromosomes in pairwise comparisons among strains. B, Total number of differentially expressed genes from accessory chromosomes in pairwise comparisons among strains. C, Genes from core chromosomes differentially upregulated at the different time points of the infection cycle. D, Genes from accessory chromosomes differentially upregulated at the different time points of the infection cycle. E, Genes from core chromosomes differentially downregulated at the different time points of the infection cycle. F, Genes from accessory chromosomes differentially downregulated at the different time points of the infection cycle. False discovery rate $\leq 0.05$ and $\log _{2}$-fold change $\geq 1$. 
play important roles in virulence and explain differences in latent periods among strains.

\section{MATERIALS AND METHODS}

\section{Plant inoculations and RNA extractions.}

Triticum aestivum 'Drifter' seedlings were inoculated with the four strains, as described previously, on the same day and in the same greenhouse chamber (Palma-Guerrero et al. 2016). The second leaf on 10 different plants was harvested at 3, 7, 10, $12,14,16,18,20,24$, and 28 dpi for each strain. Total RNA was extracted from infected leaves at four time points $(7,12,14$, and 28 dpi) using TRIzol (Invitrogen), following the manufacturer's recommendations. These four time points were chosen to include the transition from asymptomatic to necrotrophic stages of infection as well as the saprotrophic stage. The three leaf samples for each time point with the highest RNA quality according to a Bioanalyzer 2100 (Agilent) were used as biological replicates for library preparation and sequencing.

\section{Library preparation and sequencing.}

RNA quality was checked using a Qubit fluorometer (Life Technologies) and a Bioanalyzer 2100. Library preparations were performed at the Functional Genomics Center of Zurich, using the TruSeq stranded mRNA sample prep kit (Illumina Inc.), according to the kit protocol. Total RNA samples were ribosome depleted by using polyA selection and reversetranscribed into double-stranded cDNA with actinomycin added during first-strand synthesis. The cDNA was fragmented, end-repaired, and polyadenylated before ligation of TruSeq

\section{A}
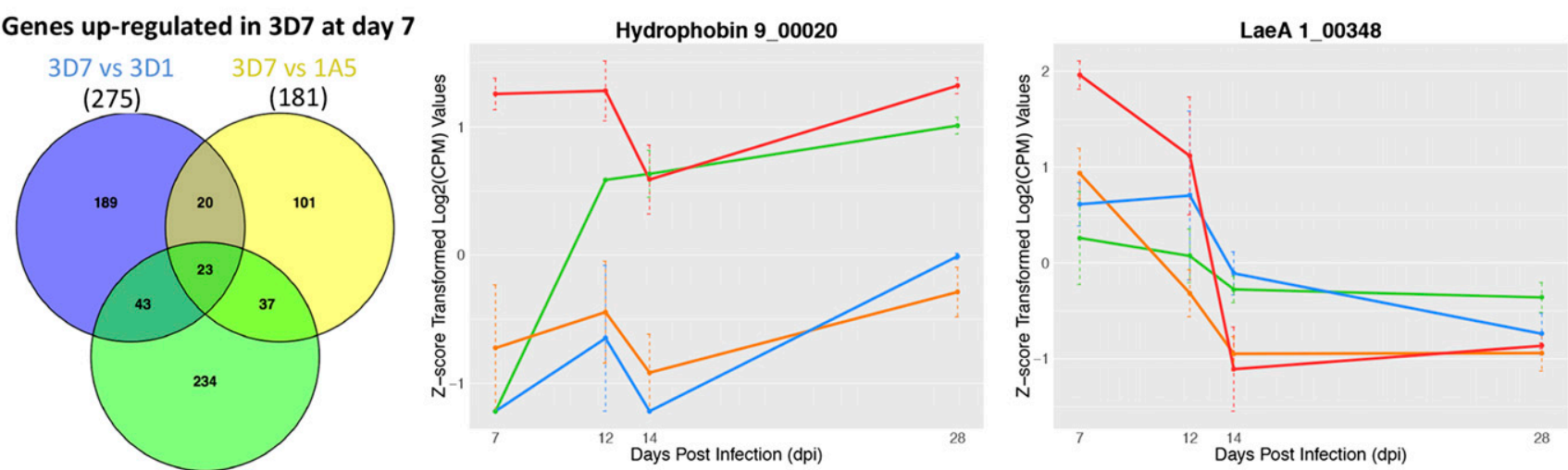

(337)

$3 D 7$ vs $1 A 5$

\section{B}

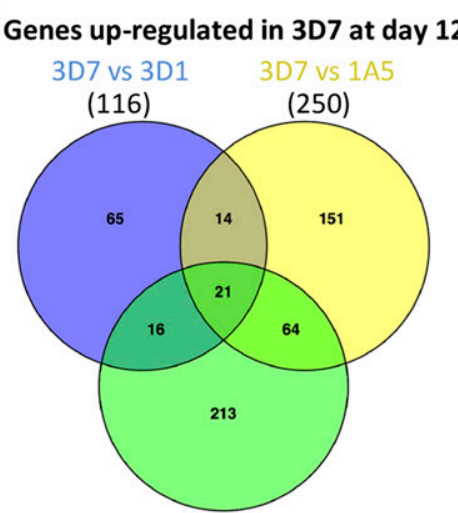

(314)

$3 D 7$ vs $1 A 5$
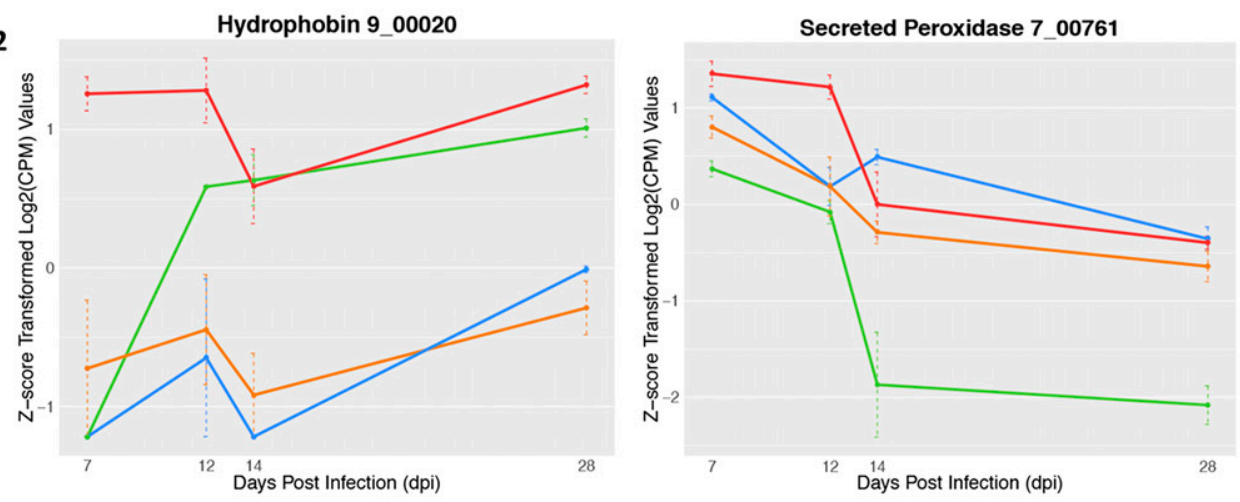

SSP 1_02089
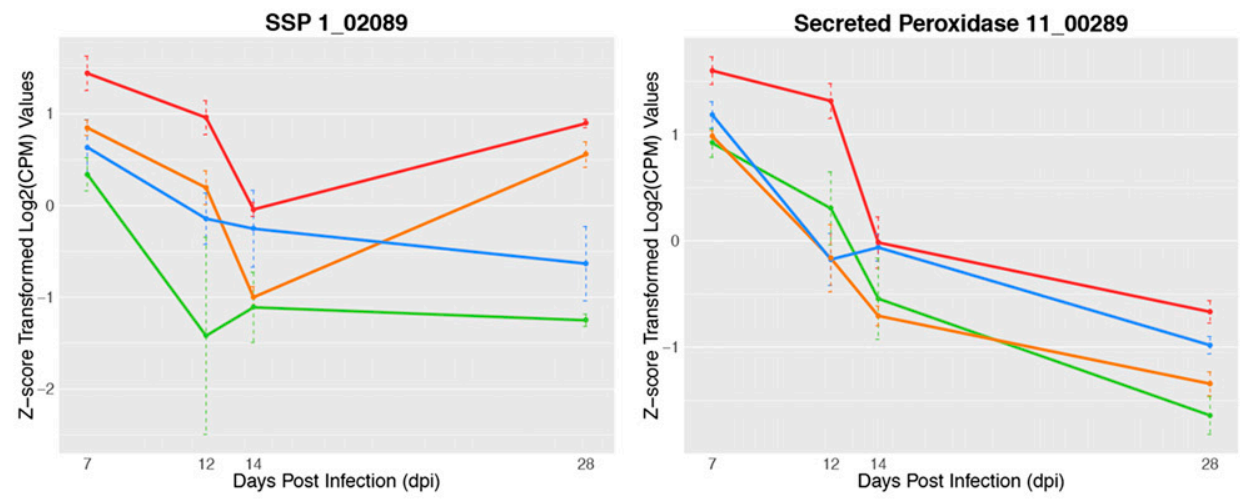

$-3 \mathrm{D} 1-3 \mathrm{D} 7 \quad-1 \mathrm{~A} 5-1 \mathrm{E} 4$

Fig. 7. Using differential expression to identify new virulence factors in Zymoseptoria tritici. Genes significantly upregulated in 3D7 compared with the other three strains at $\mathbf{A}$, day 7 and $\mathbf{B}$, day 12 . False discovery rate $\leq 0.05$ and $\log _{2}$-fold change $\geq 1$. Bars indicate standard errors. 
adapters. Fragments containing TruSeq adapters on both ends were selectively enriched with polymerase chain reaction (PCR). The quality and quantity of the enriched libraries were validated using a Qubit (1.0) fluorometer and a Tapestation (Agilent). Libraries were sequenced as paired ends on an Illumina HiSeq 2500 at $2 \times 125$ bp (Illumina, Inc.). All raw sequencing data were deposited into the NCBI Short Read Archive under the accession number SRP077418.

\section{Transcriptome mapping and quantification.}

Raw Illumina reads were quality-trimmed and filtered to remove low-quality reads, using Trimmomatic v. 0.33 (Bolger et al. 2014) with the following settings: ILLUMINACLIP:TruSeq3-PE. fa:2:30:10, LEADING:10 TRAILING:10, SLIDINGWINDOW:5: 10 MINLEN:50. Filtered reads were aligned to the IPO323 reference genome using the transcriptome aligner Tophat v. 2.0.13 (Trapnell et al. 2009) with the main parameters: "-library-type fr-firststrand," indicating the strand information for the library, and "-G Zymoseptoria_tritici.MG2.29.gff3," providing the known annotated transcripts. The reference genome sequence was retrieved from Ensembl release 26 (Kersey et al. 2016) (accessed May 2015). The other parameters for Tophat were set as default.

The Htseq-count function from HTSeq v0.6.1 (Anders et al. 2015) was used to calculate the gene counts with the "union" model. Htseq-count would exclude the mapped reads generated from Tophat with more than one reported alignment and record the numbers of these reads in the "_alignment_not_unique" features. Only the unique mapped reads were used in the downstream analysis. We set the parameter "-s reverse" to take the strand information into consideration. The latest RNA-seq based annotation was used (Grandaubert et al. 2015) (Supplementary File 1). The command we used for HTSeq was: htseqcount -f bam -s reverse mapped.bam -idattr Parent $\mathrm{Zt}$ IPO323_Stukenbrock_Annotation.gff $>$ mapped.htseq.txt. The count table from HTseq-count is provided in Supplementary File 2.

The Bioconductor edgeR v3.12.1 package (Robinson and Oshlack 2010; Robinson and Smyth 2008; Robinson et al. 2010) was used to normalize the gene counts and identify the differentially expressed genes. Only genes with average counts per million reads per sample $>1$ for at least one of the four time points in the infection cycle were considered as expressed genes. Genes without at least one read per million in at least three samples were removed before the pairwise differential gene expression analysis (Anders et al. 2013). The differentially expressed genes were determined using the "exactTest" function and were adjusted using the Benjamin-Hochberg FDR correction to account for multiple comparisons. Biological coefficient of variation plots of each pairwise comparison are provided in Supplementary Fig. S13. Details of the scripts are provided in Supplementary File 3.

\section{Transcription profile analysis.}

The library sizes were normalized with the method of TMM (Robinson and Oshlack 2010) implemented in the edgeR package. CPM (counts per million mapped reads) values and RPKM were generated by edgeR with the function "cpm" and "rpkm," respectively, based on the TMM-normalized library sizes. For RPKM values, a vector containing the length of every gene was provided. The $\log _{2}$-transformed CPM values were used to plot the gene expression density, using the CRAN sm package (Bowman and Azzalini 2014). The R package pheatmap (Kolde 2012) was used to generate the heatmaps, with the special parameter "cluster_rows=TRUE" to cluster the genes according to hierarchical clusters. To compare the expression of SSPs among the four strains, the maximum $\log _{2}$-transformed CPM values of each SSP during the disease cycle was used to generate radar figures for each SSP, using ggplot2 (Wickham 2009).

\section{Functional annotation.}

Genes were assigned to different categories according to the functional annotation of Grandaubert et al. (2015). Genes annotated as hypothetical proteins without known functions but containing InterProScan domains (Jones et al. 2014) according to Grandaubert et al. (2015) were assigned to corresponding categories, using this information. EMBOSS Pepstats (McWilliam et al. 2013) was used to calculate the percentage of cysteines. SignalP 3.0 (Emanuelsson et al. 2007) was used to calculate the length of the signal peptide for the secreted proteins. SecretomeP was used to detect proteins secreted via a nonclassical pathway (Bendtsen et al. 2004). GO terms were retrieved from the InterProScan analyses. GO enrichment analysis of differentially expressed genes was performed using the $\mathrm{R}$ package topGO v2.22.0 (Alexa and Rahnenfuhrer 2010). GO term sizes were set to contain at least five annotated genes.

\section{Gene presence or absence analysis.}

We analyzed gene presence/absence polymorphisms among the four strains using CNVnator (Abyzov et al. 2011). We mapped 100 bp Illumina short reads (NCBI BioProject PRJNA178194) to the IPO323 reference genome as described by Croll et al. (2013). CNVnator enabled a statistical analysis of short read coverage to detect copy number variation (CNV) in the four sequenced strains. For each strain, we assessed CNV events in bins of $100 \mathrm{bp}$. We retained deletion calls according to the following filtering criteria: length $>500 \mathrm{bp}, P$ value $<0.05$, normalized average read depth $<0.4$, and q0 $<0.5$. To predict a gene presence/absence polymorphism, we calculated the percentage of overlap between CNV deletion events and genes using the bedtools intersect command (Quinlan and Hall 2010). A gene was considered as absent if a CNV deletion event was overlapping in more than $90 \%$ of the coding sequences of a gene. We manually curated gene deletion calls by inspecting the match between changes in read coverage and CNV event calls in the IGV genome browser (Thorvaldsdottir et al. 2013). We validated gene deletion calls, using PCR assays for genes 8_00609, 2_00032, and 1_01966 (PKS10) in strain 3D7. Compared with the IPO323 reference genome, we identified 295, 308, 247 , and 251 genes that were absent in 1E4, 1A5, 3D7, and 3D1, respectively.

\section{ACKNOWLEDGMENTS}

We thank J. Grandaubert and E. Stukenbrock from the Max Planck Institute for Evolutionary Ecology for facilitating the RNAseq based annotation of the $Z$. tritici reference strain as well as providing the gene sequences and the InterproScan and GO information for all the gene models. We thank A. Sánchez Vallet for critical reading of the manuscript and valuable feedback. This work was supported by a fellowship to J. Palma-Guerrero from the Postdoc Fellowship Programme in Plant Sciences 'Plant Fellows' (European Union Seventh Framework Programme GA2010-267243). X. Ma was the recipient of a fellowship from the PSCSyngenta fellowship program. Laboratory facilities were provided by the Genetic Diversity Centre (GDC) of ETH Zurich. Sequencing was performed at the Functional Genomics Centre Zurich.

\section{LITERATURE CITED}

Abyzov, A., Urban, A. E., Snyder, M., and Gerstein, M. 2011. CNVnator: An approach to discover, genotype, and characterize typical and atypical CNVs from family and population genome sequencing. Genome Res. 21:974-984.

Alexa, A., and Rahnenfuhrer, J. 2010. TopGo: Enrichment analysis for Gene Ontology. R package version 2.22.0. The College of Information Sciences and Technology, The Pennsylvania State University, University Park, PA, U.S.A. 
Anders, S., McCarthy, D. J., Chen, Y., Okoniewski, M., Smyth, G. K., Huber, W., and Robinson, M. D. 2013. Count-based differential expression analysis of RNA sequencing data using $\mathrm{R}$ and Bioconductor. Nat. Protoc. 8:1765-1786.

Anders, S., Pyl, P. T., and Huber, W. 2015. HTSeq-a Python framework to work with high-throughput sequencing data. Bioinformatics 31:166-169.

Atanasova, L., Le Crom, S., Gruber, S., Coulpier, F., Seidl-Seiboth, V., Kubicek, C. P., and Druzhinina, I. S. 2013. Comparative transcriptomics reveals different strategies of Trichoderma mycoparasitism. BMC Genomics 14:121.

Bayry, J., Aimanianda, V., Guijarro, J. I., Sunde, M., and Latge, J. P. 2012. Hydrophobins-Unique fungal proteins. PLoS Pathog. 8:e1002700.

Bendtsen, J. D., Jensen, L. J., Blom, N., von Heijne, G., and Brunak, S. 2004. Feature-based prediction of non-classical and leaderless protein secretion. Protein Eng. Des. Sel. 17:349-356.

Bok, J. W., and Keller, N. P. 2004. LaeA, a regulator of secondary metabolism in Aspergillus spp. Eukaryot. Cell 3:527-535.

Bok, J. W., Balajee, S. A., Marr, K. A., Andes, D., Nielsen, K. F., Frisvad, J. C., and Keller, N. P. 2005. LaeA, a regulator of morphogenetic fungal virulence factors. Eukaryot. Cell 4:1574-1582.

Bolger, A. M., Lohse, M., and Usadel, B. 2014. Trimmomatic: A flexible trimmer for Illumina sequence data. Bioinformatics 30:2114-2120.

Bowman, A.W., and Azzalini, A. 2014. R package 'sm': Nonparametric smoothing methods (version 2.2-5.4). The R Foundation. Vienna.

Brakhage, A. A. 2013. Regulation of fungal secondary metabolism. Nat. Rev. Microbiol. 11:21-32.

Brunner, P. C., Torriani, S. F. F., Croll, D., Stukenbrock, E. H., and McDonald, B. A. 2013. Coevolution and life cycle specialization of plant cell wall degrading enzymes in a hemibiotrophic pathogen. Mol. Biol. Evol. 30:1337-1347.

Butler, M. J., and Day, A. W. 1998. Fungal melanins: A review. Can. J. Microbiol. 44:1115-1136.

Cox, R. J., and Simpson, T. J. 2009. Fungal type I polyketide synthases. Methods Enzymol. 459:49-78.

Croll, D., Zala, M., and McDonald, B. A. 2013. Breakage-fusion-bridge cycles and large insertions contribute to the rapid evolution of accessory chromosomes in a fungal pathogen. PLoS Genet. 9:e1003567.

de Jonge, R., Bolton, M. D., and Thomma, B. P. H. J. 2011. How filamentous pathogens co-opt plants: The ins and outs of fungal effectors. Curr. Opin. Plant Biol. 14:400-406.

de Villemereuil, P., Gaggiotti, O. E., Mouterde, M., and Till-Bottraud, I. 2016. Common garden experiments in the genomic era: New perspectives and opportunities. Heredity 116:249-254

do Amaral, A. M., Antoniw, J., Rudd, J. J., and Hammond-Kosack, K. E. 2012. Defining the predicted protein secretome of the fungal wheat leaf pathogen Mycosphaerella graminicola. PLoS One 7:e0049904.

Dunaevsky, Y. E., Popova, V. V., Semenova, T. A., Beliakova, G. A., and Belozersky, M. A. 2014. Fungal inhibitors of proteolytic enzymes: Classification, properties, possible biological roles, and perspectives for practical use. Biochimie 101:10-20.

Edreva, A. 2005. Pathogenesis-related proteins: Research progress in the last 15 years. Gen. Appl. Plant Physiol. 31:20.

Emanuelsson, O., Brunak, S., von Heijne, G., and Nielsen, H. 2007. Locating proteins in the cell using TargetP, SignalP and related tools. Nat. Protoc. 2:953-971.

Eyal, Z., Scharen, A. L., Prescott, J. M., and van Ginkel, M. 1987. The Septoria Diseases of Wheat: Concepts and Methods of Disease Management. International Maize and Wheat Improvement Center, Mexico D.F.

Gao, Q., Jin, K., Ying, S. H., Zhang, Y., Xiao, G., Shang, Y., Duan, Z., Hu, X., Xie, X. Q., Zhou, G., Peng, G., Luo, Z., Huang, W., Wang, B., Fang, W., Wang, S., Zhong, Y., Ma, L. J., St Leger, R. J., Zhao, G. P., Pei, Y. Feng, M. G., Xia, Y., and Wang, C. 2011. Genome sequencing and comparative transcriptomics of the model entomopathogenic fungi Metarhizium anisopliae and M. acridum. PLoS Genet. 7:e1001264.

Gohari, A. M., Ware, S. B., Wittenberg, A. H. J., Mehrabi, R., Ben M'Barek, S., Verstappen, E. C. P., Van der Lee, T. A. J., Robert, O., Schouten, H. J., De Wit, P. P. J. G. M., and Kema, G. H. J. 2015. Effector discovery in the fungal wheat pathogen Zymoseptoria tritici. Mol. Plant Pathol. 16:931-945

Goodwin, S. B., Ben M'Barek, S., Dhillon, B., Wittenberg, A. H. J., Crane, C. F., Hane, J. K., Foster, A. J., Van der Lee, T. A. J., Grimwood, J., Aerts, A., Antoniw, J., Bailey, A., Bluhm, B., Bowler, J., Bristow, J., van der Burgt, A., Canto-Canche, B., Churchill, A. C. L., Conde-Ferraez, L., Cools, H. J., Coutinho, P. M., Csukai, M., Dehal, P., De Wit, P., Donzelli, B., van de Geest, H. C., Van Ham, R. C. H. J., Hammond-Kosack, K. E., Henrissat, B., Kilian, A., Kobayashi, A. K., Koopmann, E., Kourmpetis, Y., Kuzniar, A., Lindquist, E., Lombard, V., Maliepaard, C., Martins, N., Mehrabi, R., Nap, J. P. H., Ponomarenko, A., Rudd, J. J., Salamov, A.,
Schmutz, J., Schouten, H. J., Shapiro, H., Stergiopoulos, I., Torriani, S. F. F., Tu, H., de Vries, R. P., Waalwijk, C., Ware, S. B., Wiebenga, A., Zwiers, L. H., Oliver, R. P., Grigoriev, I. V., and Kema, G. H. J. 2011 Finished genome of the fungal wheat pathogen Mycosphaerella graminicola reveals dispensome structure, chromosome plasticity, and stealth pathogenesis. PLoS Genet. 7:e1002070.

Grandaubert, J., Bhattacharyya, A., and Stukenbrock, E.H. 2015. RNA-seqbased gene annotation and comparative genomics of four fungal grass pathogens in the genus Zymoseptoria identify novel orphan genes and species-specific invasions of transposable elements. Genes Genom. Genet. 5:1323-1333.

Howlett, B. J. 2006. Secondary metabolite toxins and nutrition of plant pathogenic fungi. Curr. Opin. Plant Biol. 9:371-375.

Jones, P., Binns, D., Chang, H. Y., Fraser, M., Li, W., McAnulla, C., McWilliam, H., Maslen, J., Mitchell, A., Nuka, G., Pesseat, S., Quinn, A. F., Sangrador-Vegas, A., Scheremetjew, M., Yong, S. Y., Lopez, R., and Hunter, S. 2014. InterProScan 5: Genome-scale protein function classification. Bioinformatics 30:1236-1240.

Jorgensen, L. N., Hovmoller, M. S., Hansen, J. G., Lassen, P., Clark, B., Bayles, R., Rodemann, B., Flath, K., Jahn, M., Goral, T., Czembor, J., Cheyron, P., Maumene, C., De Pope, C., Ban, R., Nielsen, G. C., and Berg, G. 2014. IPM Strategies and Their Dilemmas Including an Introduction to http://www.eurowheat.org. J. Integr. Agr. 13:265-281.

Keller, N. P., Turner, G., and Bennett, J. W. 2005. Fungal secondary metabolism-From biochemistry to genomics. Nat. Rev. Microbiol. 3: 937-947.

Kellner, R., Bhattacharyya, A., Poppe, S., Hsu, T. Y., Brem, R. B., and Stukenbrock, E. H. 2014. Expression profiling of the wheat pathogen Zymoseptoria tritici reveals genomic patterns of transcription and hostspecific regulatory programs. Genome Biol. Evol. 6:1353-1365.

Kema, G. H. J., Yu, D. Z., Rijkenberg, F. H. J., Shaw, M. W., and Baayen, R. P. 1996. Histology of the pathogenesis of Mycosphaerella graminicola in wheat. Phytopathology 86:777-786.

Kersey, P. J., Allen, J. E., Armean, I., Boddu, S., Bolt, B. J., Carvalho-Silva, D., Christensen, M., Davis, P., Falin, L. J., Grabmueller, C., Humphrey, J., Kerhornou, A., Khobova, J., Aranganathan, N. K., Langridge, N., Lowy, E., McDowall, M. D., Maheswari, U., Nuhn, M., Ong, C. K. Overduin, B., Paulini, M., Pedro, H., Perry, E., Spudich, G., Tapanari, E., Walts, B., Williams, G., Tello-Ruiz, M., Stein, J., Wei, S., Ware, D., Bolser, D. M., Howe, K. L., Kulesha, E., Lawson, D., Maslen, G., and Staines, D. M. 2016. Ensembl genomes 2016: More genomes, more complexity. Nucleic Acids Res. 44:D574-D580.

Kim, J. Y., Park, S. C., Hwang, I., Cheong, H., Nah, J. W., Hahm, K. S., and Park, Y. 2009. Protease inhibitors from plants with antimicrobial activity. Int. J. Mol. Sci. 10:2860-2872.

Kolde, R. 2012. Pheatmap: Pretty heatmaps. R package version 061 . The $\mathrm{R}$ Foundation. Vienna.

Lee, W. S., Rudd, J. J., Hammond-Kosack, K. E., and Kanyuka, K. 2014 Mycosphaerella graminicola LysM effector-mediated stealth pathogenesis subverts recognition through both CERK1 and CEBiP homologues in wheat. Mol. Plant-Microbe Interact 27:236-243.

Lehr, N. A., Wang, Z., Li, N., Hewitt, D. A., Lopez-Giraldez, F., Trail, F., and Townsend, J. P. 2014. Gene expression differences among three Neurospora species reveal genes required for sexual reproduction in Neurospora crassa. PLoS One 9:e110398.

Lendenmann, M.H., Croll, D., Stewart, E.L., and McDonald, B.A. 2014 Quantitative trait locus mapping of melanization in the plant pathogenic fungus Zymoseptoria tritici. Genes Genom. Genet. 4:2519-2533.

Marshall, R., Kombrink, A., Motteram, J., Loza-Reyes, E., Lucas, J., Hammond-Kosack, K. E., Thomma, B. P. H. J., and Rudd, J. J. 2011 Analysis of two in planta expressed LysM effector homologs from the fungus Mycosphaerella graminicola reveals novel functional properties and varying contributions to virulence on wheat. Plant Physiol. 156:756-769.

McDonald, B. A., and Linde, C. 2002. Pathogen population genetics, evolutionary potential, and durable resistance. Annu. Rev. Phytopathol. 40:349-379.

McWilliam, H., Li, W. Z., Uludag, M., Squizzato, S., Park, Y. M., Buso, N., Cowley, A. P., and Lopez, R. 2013. Analysis tool web services from the EMBL-EBI. Nucleic Acids Res. 41:W597-W600.

Mueller, A. N., Ziemann, S., Treitschke, S., Assmann, D., and Doehlemann, G. 2013. Compatibility in the Ustilago maydis-maize interaction requires inhibition of host cysteine proteases by the fungal effector Pit2. PLoS Pathog. 9:e1003177.

Neumann, C. S., Fujimori, D. G., and Walsh, C. T. 2008. Halogenation strategies in natural product biosynthesis. Chem. Biol. 15:99-109.

O'Driscoll, A., Kildea, S., Doohan, F., Spink, J., and Mullins, E. 2014. The wheat-Septoria conflict: A new front opening up? Trends Plant Sci. 19: 602-610. 
Ohm, R. A., Feau, N., Henrissat, B., Schoch, C. L., Horwitz, B. A., Barry, K. W., Condon, B. J., Copeland, A. C., Dhillon, B., Glaser, F., Hesse, C. N., Kosti, I., LaButti, K., Lindquist, E. A., Lucas, S., Salamov, A. A., Bradshaw, R. E., Ciuffetti, L., Hamelin, R. C., Kema, G. H. J., Lawrence, C., Scott, J. A., Spatafora, J. W., Turgeon, B. G., de Wit, P. J. G. M., Zhong, S. B., Goodwin, S. B., and Grigoriev, I. V. 2012. Diverse lifestyles and strategies of plant pathogenesis encoded in the genomes of eighteen Dothideomycetes fungi. PLoS Pathog. 8:e1003037.

Oleksiak, M. F., Churchill, G. A., and Crawford, D. L. 2002. Variation in gene expression within and among natural populations. Nat. Genet. 32: 261-266.

Palma-Guerrero, J., Torriani, S. F., Zala, M., Carter, D., Courbot, M., Rudd, J. J., McDonald, B. A., and Croll, D. 2016. Comparative transcriptome analyses of Zymoseptoria tritici strains show complex lifestyle transitions and intra-specific variability in transcription profiles. Mol. Plant Pathol. 17:845-859

Poppe, S., Dorsheimer, L., Happel, P., and Stukenbrock, E. H. 2015. Rapidly evolving genes are key players in host specialization and virulence of the fungal wheat pathogen Zymoseptoria tritici (Mycosphaerella graminicola). PLoS Pathog. 11:e1005055.

Quinlan, A. R., and Hall, I. M. 2010. BEDTools: A flexible suite of utilities for comparing genomic features. Bioinformatics 26:841-842.

Rep, M. 2005. Small proteins of plant-pathogenic fungi secreted during host colonization. FEMS Microbiol. Lett. 253:19-27.

Robinson, M. D., and Oshlack, A. 2010. A scaling normalization method for differential expression analysis of RNA-seq data. Genome Biol. 11: $\mathrm{R} 25$.

Robinson, M. D., and Smyth, G. K. 2008. Small-sample estimation of negative binomial dispersion, with applications to SAGE data. Biostatistics 9:321-332.

Robinson, M. D., McCarthy, D. J., and Smyth, G. K. 2010. edgeR: A Bioconductor package for differential expression analysis of digital gene expression data. Bioinformatics 26:139-140.

Rudd, J. J. 2015. Previous bottlenecks and future solutions to dissecting the Zymoseptoria tritici-wheat host-pathogen interaction. Fungal Genet. Biol. 79:24-28.

Rudd, J. J., Kanyuka, K., Hassani-Pak, K., Derbyshire, M., Andongabo, A., Devonshire, J., Lysenko, A., Saqi, M., Desai, N. M., Powers, S. J., Hooper, J., Ambroso, L., Bharti, A., Farmer, A., Hammond-Kosack, K. E., Dietrich, R. A., and Courbot, M. 2015. Transcriptome and metabolite profiling of the infection cycle of Zymoseptoria tritici on Wheat reveals a biphasic interaction with plant immunity involving differential pathogen chromosomal contributions and a variation on the hemibiotrophic lifestyle definition. Plant Physiol. 167:1158.

Scott, P. R., Sanderson, F. R., and Benedikz, P. W. 1988. Occurrence of Mycosphaerella-graminicola, teleomorph of Septoria tritici, on wheat debris in the UK. Plant Pathol. 37:285-290.

Stewart, E. L., and McDonald, B. A. 2014. Measuring quantitative virulence in the wheat pathogen Zymoseptoria tritici using highthroughput automated image analysis. Phytopathology 104:985-992.

Stewart, E. L., Croll, D., Lendenmann, M. H., Sanchez-Vallet, A., Hartmann, F. E., Palma-Guerrero, J., Ma, X., and McDonald, B. A. 2017. QTL mapping reveals complex genetic architecture of quantitative virulence in the wheat pathogen Zymoseptoria tritici. Mol. Plant Pathol. Published online. doi:10.1111/mpp.12515

Subramoni, S., Suárez-Moreno, Z. R., and Venturi, V. 2010. Lipases as pathogenicity factors of plant pathogens. Pages 3269-3277 in: Handbook of Hydrocarbon and Lipid Microbiology. K. N. Timmis, ed. Springer, Berlin.

Terabayashi, Y., Shimizu, M., Kitazume, T., Masuo, S., Fujii, T., and Takaya, N. 2012. Conserved and specific responses to hypoxia in Aspergillus oryzae and Aspergillus nidulans determined by comparative transcriptomics. Appl. Microbiol. Biotechnol. 93:305-317.

Thorvaldsdottir, H., Robinson, J. T., and Mesirov, J. P. 2013. Integrative Genomics Viewer (IGV): High-performance genomics data visualization and exploration. Brief. Bioinform. 14:178-192.

Torriani, S. F., Stukenbrock, E. H., Brunner, P. C., McDonald, B. A., and Croll, D. 2011. Evidence for extensive recent intron transposition in closely related fungi. Curr. Biol. 21:2017-2022.

Trapnell, C., Pachter, L., and Salzberg, S. L. 2009. TopHat: Discovering splice junctions with RNA-Seq. Bioinformatics 25:1105-1111.

Whitehead, A., and Crawford, D. L. 2006. Variation within and among species in gene expression: Raw material for evolution. Mol. Ecol. 15: 1197-1211.

Wickham, H. 2009. ggplot2: Elegant Graphics for Data Analysis. Pages: 1-212 in: Use R. Springer-Verlag, New York.

Wittenberg, A. H., van der Lee, T. A., Ben M'barek, S., Ware, S. B., Goodwin, S. B., Kilian, A., Visser, R. G., Kema, G. H., and Schouten, H. J. 2009. Meiosis drives extraordinary genome plasticity in the haploid fungal plant pathogen Mycosphaerella graminicola. PLoS One 4:e5863.

Zhan, J., and McDonald, B. A. 2004. The interaction among evolutionary forces in the pathogenic fungus Mycosphaerella graminicola. Fungal Genet. Biol. 41:590-599.

Zhan, J., Mundt, C. C., Hoffer, M. E., and McDonald, B. A. 2002. Local adaptation and effect of host genotype on the rate of pathogen evolution: An experimental test in a plant pathosystem. J. Evol. Biol. 15:634-647.

Zhan, J., Pettway, R. E., and McDonald, B. A. 2003. The global genetic structure of the wheat pathogen Mycosphaerella graminicola is characterized by high nuclear diversity, low mitochondrial diversity, regular recombination, and gene flow. Fungal Genet. Biol. 38:286-297.

Zhan, J., Linde, C. C., Jurgens, T., Merz, U., Steinebrunner, F., and McDonald, B. A. 2005. Variation for neutral markers is correlated with variation for quantitative traits in the plant pathogenic fungus Mycosphaerella graminicola. Mol. Ecol. 14:2683-2693.

Zhan, J., Torriani, S. F., and McDonald, B. A. 2007. Significant difference in pathogenicity between MAT1-1 and MAT1-2 isolates in the wheat pathogen Mycosphaerella graminicola. Fungal Genet. Biol. 44: 339-346.

\section{AUTHOR-RECOMMENDED INTERNET RESOURCES}

EMBOSS open source software analysis package: http://emboss.sourceforge.net SecretomeP website: http://www.cbs.dtu.dk/services/SecretomeP SignalP 3.0 website: http://www.cbs.dtu.dk/services/SignalP-3.0 